\title{
The Economic Value of Fundamental and Technical Information in Emerging Currency Markets
}

\author{
Gerben de Zwart, Thijs Markwat, Laurens Swinkels \\ and Dick van Dijk
}

\begin{tabular}{|l|l|}
\hline \multicolumn{2}{|l|}{ ERIM REPORT SERIES RESEARCHINMANAGMENT } \\
\hline ERIM Report Series reference number & ERS-2007-096-F\&A \\
\hline Publication & August 2008 \\
\hline Number of pages & 41 \\
\hline Persistent paper URL & http://hdl.handle.net/1765/10891 \\
\hline Email address corresponding author & djvandijk@few.eur.nl \\
\hline Address & Erasmus Research Institute of Management (ERIM) \\
& RSM Erasmus University / Erasmus School of Economics \\
& Erasmus Universiteit Rotterdam \\
& P.O.Box 1738 \\
& 3000 DR Rotterdam, The Netherlands \\
& Phone: $\quad+31104081182$ \\
& Fax: $\quad+31104089640$ \\
& Email: info@erim.eur.nl \\
& Internet: $\quad$ www.erim.eur.nl \\
\hline
\end{tabular}

Bibliographic data and classifications of all the ERIM reports are also available on the ERIM website: www.erim.eur.n 


\section{ERASMUS RESEARCH INSTITUTE OF MANAGEMENT}

\section{REPORT SERIES}

\section{RESEARCH IN MANAGEMENT}

\begin{tabular}{|c|c|}
\hline \multicolumn{2}{|c|}{ ABSTRACT AND KEYWORDS } \\
\hline Abstract & $\begin{array}{l}\text { We measure the economic value of information derived from macroeconomic variables and from } \\
\text { technical trading rules for emerging markets currency investments. Our analysis is based on a } \\
\text { sample of } 21 \text { emerging markets with a floating exchange rate regime over the period } 1997-2007 \\
\text { and explicitly accounts for trading restrictions on foreign capital movements by using non- } \\
\text { deliverable forward data. We document that both types of information can be exploited to } \\
\text { implement profitable trading strategies. In line with evidence from surveys of foreign exchange } \\
\text { professionals concerning the use of fundamental and technical analysis, we find that combining } \\
\text { the two types of information improves the risk-adjusted performance of the investment } \\
\text { strategies. }\end{array}$ \\
\hline Free Keywords & $\begin{array}{l}\text { emerging markets, foreign exchange rates, structural exchange rate models, technical trading, } \\
\text { heterogeneous agents }\end{array}$ \\
\hline Availability & $\begin{array}{l}\text { The ERIM Report Series is distributed through the following platforms: } \\
\text { Academic Repository at Erasmus University (DEAR), DEAR ERIM Series Portal } \\
\text { Social Science Research Network (SSRN), SSRN ERIM Series Webpage } \\
\text { Research Papers in Economics (REPEC), REPEC ERIM Series Webpage }\end{array}$ \\
\hline Classifications & $\begin{array}{l}\text { The electronic versions of the papers in the ERIM report Series contain bibliographic metadata } \\
\text { by the following classification systems: } \\
\text { Library of Congress Classification, (LCC) LCC Webpage } \\
\text { Journal of Economic Literature, (JEL), JEL Webpage } \\
\text { ACM Computing Classification System CCS Webpage } \\
\text { Inspec Classification scheme (ICS), ICS Webpage }\end{array}$ \\
\hline
\end{tabular}




\title{
The Economic Value of Fundamental and Technical Information in Emerging Currency Markets*
}

\author{
Gerben de Zwart ${ }^{\dagger}$ \\ ING Investment Management and \\ RSM Erasmus University \\ Laurens Swinkels \\ Robeco Quantitative Strategies and \\ Erasmus Research Institute of Management
}

\author{
Thijs Markwat \\ Econometric Institute and \\ Erasmus Research Institute of Management \\ Dick van Dijk \\ Econometric Institute \\ Erasmus University Rotterdam
}

August 2008

\begin{abstract}
We measure the economic value of information derived from macroeconomic variables and from technical trading rules for emerging markets currency investments. Our analysis is based on a sample of 21 emerging markets with a floating exchange rate regime over the period 1997-2007 and explicitly accounts for trading restrictions on foreign capital movements by using nondeliverable forward data. We document that both types of information can be exploited to implement profitable trading strategies. In line with evidence from surveys of foreign exchange professionals concerning the use of fundamental and technical analysis, we find that combining the two types of information improves the risk-adjusted performance of the investment strategies.
\end{abstract}

Keywords: Emerging markets, Foreign exchange rates, Structural exchange rate models, Technical trading, Heterogeneous agents

JEL Classification: C53, F31, G15

*We are grateful to Kees Bouwman, Ron Jongen, April Knill, George Leledakis, Michael Melvin, Martin Prins, Marno Verbeek and an anonymous referee for helpful suggestions. We would also like to thank participants of the 1st Conference on Heterogeneous Agents in Financial Markets (Radboud University Nijmegen, January 2007), the 1st workshop of the Nonlinear Economics and Finance Research Community (Keele University, February 2007), the 2nd EMG Conference on Emerging Markets Finance (Cass Business School, May 2008), the 6th INFINITI Conference on International Finance (Trinity College, May 2008), the 35th EFA annual meeting (Athens, August 2008), and seminar participants at the University of Groningen. We are grateful to Robeco and an anonymous broker for providing data.

${ }^{\dagger}$ Corresponding Author: ING Investment Management, P.O. Box 90470, NL-2509 LL Den Haag, The Netherlands. E-mail addresses are gerben.de.zwart@ingim.nl, markwat@few.eur.nl, lswinkels@few.eur.nl, and djvandijk@few.eur.nl 


\title{
The Economic Value of Fundamental and Technical Information in Emerging Currency Markets
}

\author{
August 2008
}

\begin{abstract}
We measure the economic value of information derived from macroeconomic variables and from technical trading rules for emerging markets currency investments. Our analysis is based on a sample of 21 emerging markets with a floating exchange rate regime over the period 1997-2007 and explicitly accounts for trading restrictions on foreign capital movements by using nondeliverable forward data. We document that both types of information can be exploited to implement profitable trading strategies. In line with evidence from surveys of foreign exchange professionals concerning the use of fundamental and technical analysis, we find that combining the two types of information improves the risk-adjusted performance of the investment strategies.
\end{abstract}

Keywords: Emerging markets, Foreign exchange rates, Structural exchange rate models, Technical trading, Heterogeneous agents

JEL Classification: C53, F31, G15 


\section{Introduction}

The literature on exchange rate forecasting has extensively analyzed the predictive content of two types of information: news on macroeconomic fundamentals as used in structural exchange rate models, and information from historical prices as used in technical trading rules. Meese and Rogoff's (1983) finding that structural models cannot outperform a naive random walk forecast at short horizons still stands after 25 years of intense research, see Cheung et al. (2005) for a recent assessment. There is somewhat more supportive evidence for the usefulness of macroeconomic information for forecasting exchange rates at longer horizons, see Mark (1995), Kilian (2001) and Berkowitz and Giorgianni (2001), among others. In general, the performance of technical trading rules at short horizons has been found to be considerably better, see Sweeney (1986), Levich and Thomas (1993) and Neely and Weller (1999), with Park and Irwin (2007) and Menkhoff and Taylor (2007) providing recent comprehensive surveys. Nevertheless, Olson (2004), Pukthuanthong-Le et al. (2007) and Neely et al. (in press) report that the profitability of technical trading rules has weakened substantially in recent years, at least for developed currencies.

The predictive ability of structural exchange rate models and technical trading rules has generally been considered in isolation. This is quite remarkable, in the sense that surveys among foreign exchange market participants invariably indicate that they regard both types of information to be important factors for determining future exchange rate movements, see Taylor and Allen (1992), Menkhoff (1997), Lui and Mole (1998), Cheung and Chinn (2001), and Gehrig and Menkhoff (2004). Not surprisingly then, most foreign exchange professionals use some combination of fundamental analysis and technical analysis for their own decision making, with the relative weight given to technical analysis becoming smaller as the forecasting (or investment) horizon becomes longer.

The weights assigned to fundamental and technical information for a given horizon may also vary over time. For example, Frankel and Froot (1990) provide empirical evidence for the switch of many professional forecasters from being "fundamentalists" (using structural models and macro data) to acting as "chartists" (using technical trading rules) during the second half of the 1980s. They motivate this changing behavior by the fact that fundamentalists experienced large negative 
returns in the mid-1980s, when currency prices strongly deviated from their fundamental values. This idea of switching behavior has more recently been formalized in so-called heterogeneous agents models. Brock and Hommes (1997, 1998) develop equilibrium models in which agents update their beliefs about the future profitability of investment strategies based on their past performance. These models show that rational investors can switch between simple (costless) strategies and sophisticated (costly) strategies. When all investors follow the simple strategy prices may diverge from their fundamental value, making it worthwhile for investors to engage in sophisticated strategies, because expected profits increase. Prices are then pushed back to their fundamental value and the expected net profits for sophisticated investors turn negative. This leads them to switch back to simple and costless strategies that might again result in prices moving away from their fundamental value. These heterogeneous agents models have recently been applied to currency markets, explicitly allowing for the presence of both chartists and fundamentalists, see Chiarella et al. (2006), and De Grauwe and Grimaldi (2005, 2006). The relative importance of these two types of traders (and, hence, the two types of information) varies over time as investors are assumed to switch between strategies according to their relative past performance. De Grauwe and Markiewicz (2006) offer an alternative interpretation of these models, in which market participants combine technical analysis and fundamental information in order to forecast future foreign exchange rates, with weights varying over time as a function of past profitability.

Most research on exchange rate forecasting has focused on developed markets. Scarcely any attention has been paid to emerging market currencies, possibly due to the fact that many emerging countries maintained a fixed or pegged exchange rate regime until fairly recently. ${ }^{1}$ Since the mid-1990s, approximately, more and more countries have switched to a floating exchange rate regime. Simultaneously, the emerging currency markets became tradable for currency investors in either the deliverable forward market for currencies without trading restrictions or the nondeliverable forward (NDF) market for currencies with restrictions on foreign capital movements. By now the time series length as well as the cross-sectional breadth

\footnotetext{
${ }^{1}$ One aspect of exchange rate forecasting in emerging markets that did receive ample attention in the past is prediction of currency crises, in particular by means of so-called early warning systems, see Kaminsky (2006) for a detailed overview.
} 
are sufficient to warrant a meaningful investigation of exchange rate predictability in emerging markets. To the best of our knowledge we are the first to conduct such an analysis. Previous empirical research on heterogeneous agents models has also been limited to developed currency markets, such as Vigfusson (1997) and De Jong et al. (2006). These studies report only limited empirical evidence supporting the switching behavior between fundamentalist and chartist strategies based on past performance that is assumed in the theoretical models.

In this paper we conduct a comprehensive analysis of the economic value of technical and fundamental information in emerging currency markets. Specifically, we assess the performance of currency trading strategies based on monthly fundamental information derived from the real interest rate differential and GDP growth, as well as technical information in the form of daily moving average trading rules and support and resistance trading rules. We implement these strategies for all freely floating emerging market currencies relative to the US dollar over the period 1997-2007 and use the appropriate historical NDF data for currencies with trading restrictions. We also consider combined strategies in which both chartist and fundamentalist information are used, in line with the actual behavior of market participants, as discussed above. In particular, we examine a dynamic combination scheme with time-varying weights according to the relative profitability of the fundamental and technical strategies. As a benchmark we employ a naive strategy that assigns constant and equal weights to the two types of information. Throughout the empirical analysis, we also consider nine developed currencies as a control sample.

Our results can be summarized as follows. First, both fundamentalist and chartist strategies generate economically and statistically significant Sharpe ratios for emerging currency markets. This finding is consistent with McNown and Wallace (1989), who document that fundamentalist trading strategies perform well in four emerging markets over the period 1972-1986. Our positive results for technical trading rules provide out-of-sample evidence for the profits described by Martin (2001) and Lee et al. (2001a) for the early 1990s.

Second, we document that naively combining chartist and fundamentalist strategies generates positive risk-adjusted returns that are both economically and statistically significant. Moreover, the performance of the combined strategy is much more consistent and stable across currencies than the individual fundamentalist and 
chartist strategies. This provides convincing evidence for the complementary value of technical and fundamental information as suggested by questionnaires among currency traders. The dynamic combined strategies, where the weights assigned to fundamentalist and chartist strategies vary according to their past performance, increase the profitability of the trading strategy relative to the naive combination only modestly. Thus, we find only limited support for the enhanced profitability of the investment strategies based on the heterogeneous agents models of Chiarella et al. (2006) and De Grauwe and Grimaldi (2005, 2006).

Third, for developed currency markets we find that fundamental trading strategies render statistically and economically significant Sharpe ratios, but this is not the case for the chartist strategies. This result is in line with Abhyankar et al. (2005), who conclude that investors may benefit from fundamental exchange rate models trading the US dollar against the Canadian dollar, Japanese Yen, and British Pound over the period 1977-2000. It also corroborates the findings of Olson (2004), Pukthuanthong-Le et al. (2007) and Neely et al. (in press), who document that returns to technical trading strategies in developed markets have declined over time. We do find substantial benefits from adding emerging currencies to the developed currency strategies. For either the fundamental, chartist as well as the combined strategy, diversifying across these two types of markets leads to a significantly higher Sharpe ratio compared to the strategies that are limited to developed currencies only.

The remainder of this paper is organized as follows. In Section 2 we describe the data. We examine the performance of the fundamentalist and chartist strategies individually in Sections 3 and 4, respectively. In Section 5 we integrate the chartist and fundamentalist information into combined strategies. Finally, we conclude in Section 6 .

\section{Data description}

Our analysis is most relevant for exchange rates under a free float, as currency prices in this system are determined in principle by demand and supply, although intervention activities of central banks cannot be ruled out completely. ${ }^{2}$ Data before

\footnotetext{
${ }^{2}$ We refer to the conference notes of the IMF 'High-Level seminar on exchange rate regimes: Hard peg or free floating?' for an overview of central bank intervention activity in the emerging
} 
1997 is thus not considered, as most of the countries in our sample adopted a floating exchange rate regime around that time or later, or were not tradable for speculators. ${ }^{3}$ In total we examine the currencies of 21 emerging markets which currently have a (managed) floating exchange rate system: the Argentine peso, Brazilian real, Chilean peso, Colombian peso, Mexican peso and Peruvian sol from Latin-America; the Indian rupee, Indonesian rupiah, Korean won, Malaysian ringitt, Phillipine peso, Taiwanese dollar and Thai bath from Asia; and the Czech koruna, Hungarian forint, Israeli shekel, Polish zloty, Romanian leu, Slovak koruna, South African rand, and Turkish lira from Europe, Middle-East, and Africa (EMEA). All of these currencies became floating and tradable (before or) at some point between January 1997 and June 2007. Figure 1 shows the historical development of the number of emerging market countries with a floating exchange rate regime in our sample. The number of floating currencies starts at only five in January 1997, but increases rapidly during the first years of our sample period reaching 19 in January 2002. The exact dates of the currencies' floats are given in Table 1. Apart from the Peruvian sol all currencies were tradable at the moment they became floating.

\section{- insert Figure 1 about here -}

We employ daily and monthly exchange rates for the technical trading rules and the fundamental models, respectively. The exchange rates correspond to Reuters 07:00 GMT middle rate fixings against the US dollar. ${ }^{4}$ All exchange rates are expressed in the standard way, that is, as the price of one US dollar in the emerging market currency. The sample period runs from January 1, 1997 to June 30, 2007 (2738 daily and 126 monthly observations), where it is to be understood that each currency is included in the analysis only six months after the start of its floating

currency markets, see http://www.imf .org/external/pubs/ft/seminar/2001/err/eng/.

${ }^{3}$ In the late 1980s many emerging market countries pegged their currency to the US dollar or a basket of developed currencies to achieve price stability after a period of (hyper-)inflation. Some countries used a crawling peg, where the currency was allowed to depreciate at a steady rate such that the local inflation rate could be higher than the pegged rate. A side effect of the emerging markets currency crises during the 1990s has been that most emerging markets changed their exchange rate system from a pegged to a floating regime. Currently, only a small number of emerging market countries still maintain a (crawling) peg regime: China (pegged to the US dollar), Russia (pegged to a basket of the US dollar and euro), Vietnam (US dollar) and Pakistan (US dollar).

${ }^{4}$ Results for the Eastern European currencies (CZK, SKK, PLN, HUF and RON) relative to the EUR are similar and available upon request. 
exchange rate regime. In practice, most investors will hold off investing in a currency for some time to avoid the often dramatic exchange rate movements immediately following the float of a currency. The market has sufficiently 'cooled down' after about half a year for most currencies.

A common instrument that can be used for sec investments in the currency market is the currency forward contract. This enables investors to invest in a currency without owning any underlying assets such as bonds or stocks in the country. With the help of the forward contract currency investors lock in a specific foreign exchange rate in the future. The investment return on a currency is then defined as the difference between this forward rate and the future spot rate:

$$
r_{t}=s_{t}-f_{t-1, t}
$$

where $s_{t}$ is the log spot rate at time $t$ and $f_{t-1, t}$ is the log forward rate at time $t-1$ maturing at time $t$. In the absence of arbitrage opportunities, the forward rate is given by:

$$
F_{t-1, t}=S_{t-1} \exp \left(i_{t-1}^{E M}-i_{t-1}^{U S}\right)
$$

where $i_{t-1}^{E M}$ and $i_{t-1}^{U S}$ are the cash interest rates in the emerging country and the US, respectively. The cash rate is generally the deposit rate for money deposited in the currency and maturity that matches the maturity of the forward contract, for example the London Interbank Offered Rate (LIBOR) for US dollars. ${ }^{5}$ Substitution of (2) in (1) leads to the return on a foreign exchange investment:

$$
r_{t}=s_{t}-s_{t-1}+i_{t-1}^{U S}-i_{t-1}^{E M}
$$

Many studies on trading strategies for developed exchange rate markets disregard the interest rate differential as the influence on profitability is found to be negligible, see Sweeney (1986), LeBaron (1999), and Okunev and White (2003), among others. For emerging markets the interest rate differentials can be substantial, as shown below, and therefore should be taken into account for a fair judgement of the investment returns.

\footnotetext{
${ }^{5}$ The cash rates are quoted on an annualized basis. For our return calculations the cash rates are scaled to the a daily or monthly basis by dividing the rate by 360 days and multiplying by the number of days that a position will be held.
} 
Not all currencies in our sample have freely tradable forward markets due to foreign exchange convertibility restrictions and capital controls. Twelve emerging market currencies in our sample are traded as non-deliverable forwards (NDF): the Argentine peso, Brazilian real, Chilean peso, Colombian peso, and Peruvian sol from Latin-America; the Indian rupee, Indonesian rupiah, Korean won, Malaysian ringitt, Phillipine peso, Taiwanese dollar and Thai bath from Asia. ${ }^{6}$ An NDF is similar to a deliverable forward. The difference is that no physical delivery of the local currency takes place at maturity, but that the contract is settled by making a net payment in US dollar or another convertible currency. This payment is proportional to the difference between the agreed forward rate and the realised spot rate (fixing). Additionally, NDFs trade in offshore markets outside the direct jurisdiction of the authorities of the corresponding currencies.

The pricing of NDFs is not constrained to the domestic interest rates. In fact the NDF-implied offshore yields often differ from the onshore interest rates because NDF prices are also affected by supply and demand, liquidity, perceived probability of changes in the foreign exchange regime, and speculative positions. The covered interest rate parity often does not hold as arbitrage cannot take place due to the imposed restrictions. The implied offshore yields are not constrained by a zero lower bound and could even be negative. A large and persistent spread between the onshore yield and the NDF-implied offshore yield suggests the presence of effective restrictions leading to segmented onshore and offshore markets. ${ }^{7}$

Large international banks started providing an offshore market in NDFs for many emerging market currencies in the early 1990s with full scale trading since the mid1990s. NDF trading started for Latin American currencies, while the market later expanded to European and Asian currencies. Trading mainly takes place in the major offshore financial centers: Singapore for Asian NDFs, New York for Latin American NDFs and London. Both investors who want to take speculative currency positions or need to hedge currency exposure are present in the NDF markets, al-

\footnotetext{
${ }^{6}$ Capital controls were introduced for the Indonesian rupiah in 2000 and Thai bath in 2007. Prior to these dates both currencies were deliverable. Two currencies in our sample started their float as non-deliverable but became deliverable at some point during our sample period: the Israeli shekel (deliverable since 1998) and Romanian leu (deliverable since 2005).

${ }^{7}$ The interpretation of the onshore/offshore yield differences are complicated by credit rating differences between the offshore global banks and the sovereigns.
} 
though speculative demand dominates by generating as much as 60 to 80 percent of NDF trading volume, see Lipscomb (2005).

For our return calculations in (3) we use the historical implied interest rates from offshore NDF contracts for the non-deliverable currencies and local rates for the deliverable currencies. We obtain interbank interest rates for the deliverable currencies from Bloomberg and implied interest rates for the non-deliverable currencies from Bloomberg and an anonymous broker. The advantage of two data sources for the NDF currencies is that this enables cross-checking the implied interest rates to get a high quality data-set. Based on the cross-checks we remove a few outliers if only one source showed an outlier. We use the average yield from Bloomberg and the anonymous broker in our calculations. ${ }^{8}$

\section{- insert Table 1 about here -}

Summary statistics for the monthly returns of the emerging markets currencies are reported in Table 1. ${ }^{9}$ The Turkish lira has the best performance with an annualized mean return of 29.2 percent per year, relative to the US dollar. Note that the Turkish lira spot exchange rate hardly moved during its floating period (February 2001 - June 2007), such that these returns are due almost completely to the interest rate differential of 29.0 percent per year. The Taiwanese dollar has the worst performance with an average return of -1.62 percent per year. The annualized standard deviations of the monthly returns range between a low of 3.5 percent for the Peruvian sol (November 1999 - June 2007) and Malaysian ringitt (July 2005 - June 2007) and a high of 26.4 percent for the Indonesian Rupiah (August 1997 - June 2007). For 10 of the 21 currencies the kurtosis is (much) higher than three, indicating a high peak and fat tails in the empirical distribution of the returns relative to a normal distribution. The tail behavior of emerging market currencies is studied in detail by Candelon and Straetmans (2006). Unreported results for the Jarque-Bera test show that almost none of the currency returns are Gaussian, due to the high kurtosis and

\footnotetext{
${ }^{8}$ Interest rates are available for different maturities. We use the three-month rates because our final trading strategy (see Section 5) holds its positions for three months on average. All interest rates are reported on an annualized basis. For daily performance evaluation we use the 'actual/360' day count convention for all countries.

${ }^{9}$ The (unreported) descriptive statistics for the daily returns show similar patterns, although the kurtosis is higher. This corresponds quite well with the stylized fact of asset returns that nonnormality (in particular peakedness and fat tails) becomes more pronounced at higher frequencies.
} 
the nonzero skewness. The example of the Turkish lira mentioned above already suggests that we should not disregard the interest rate differential when computing the investment return on the emerging market currencies. This is confirmed by the last two columns of Table 1, showing that the average interest rate differential is even larger than the spot rate return for 12 out of 21 currencies.

Table 1 also includes summary statistics for our developed markets control sample. This sample holds the G10 currencies: Australian dollar, Canadian dollar, UK pound, Japanese yen, Euro, Swiss franc, Norwegian krone, Swedish krona, and the New Zealand dollar, all relative to the US dollar. We use the German Deutschmark for the history of the euro prior to 1999. The New Zealand dollar performs best with an annualized return of 3.0 percent. The Japanese yen shows the worst performance with an average return of -4.4 percent per year. The average volatility is 9.6 percent, with much less variation across currencies than for the emerging markets.

Finally, we compute cross-correlations of the monthly returns. The average correlation between all possible pairs of emerging market exchange rates is 0.21 . Most correlations are in fact close to zero, although some currencies within the same region have a correlation of up to 0.50 for Asia and 0.75 for Europe. These low correlations are advantageous for our empirical analysis, as it means that the trading strategies can benefit from diversification if we combine the currencies in a portfolio. The cross-correlations among emerging market currencies are considerably lower than those for the developed exchange rates, which generally exceed 0.75. For example, the correlation between the euro and Swiss Franc is equal to 0.95. The main exception is the correlation of the Japanese yen with the other developed currencies, which is substantially lower and equals 0.32 on average.

\section{$3 \quad$ Fundamentalist trading strategies}

Fundamentalists believe that the exchange rate is intimately linked to macroeconomic variables such as output, inflation, and the trade balance, among others. Under this paradigm, news in these economic "fundamentals" is responsible for exchange rate movements. A wide variety of structural exchange rate models is available that might be used for forecasting the future exchange rate. Cheung et al. (2005) conclude that "old-fashioned", basic structural models, such as the real in- 
terest rate differential (see Frankel (1979), for example) perform at least as good as more recent, elaborate models. This motivates us to use relatively simple structural models in our empirical analysis. In particular, we assume that fundamentalists derive their exchange rate forecasts from information on the real interest rate differential and the growth rate of GDP. ${ }^{10}$ Furthermore, we do not explicitly estimate regression models that include these variables like Garratt and Lee (2007). Instead we simply use them to generate buy and sell signals for the different currencies based on a prediction of the sign of the exchange rate return in the next month, as explained in detail below. On the one hand, this is motivated by the fact that the time period during which the emerging market currencies are floating generally is already rather short. Using part of the available sample for model estimation would leave only a very limited number of observations for out-of-sample forecasting. On the other hand, as pointed out by Leitch and Tanner (1991), among others, correctly forecasting the direction of asset price movements is more crucial than forecasting their magnitude when it comes to economic forecast evaluation measures such as the performance of trading strategies.

The two macroeconomic variables are used to generate buy and sell signals as follows. First, we take a long (short) position in the emerging market currency if its real interest rate is above (below) the US one. Given the high inflation in emerging markets we do not consider the difference in nominal interest rates but the real interest differential, see Isaac and de Mel (2001) for discussion. Furthermore, in order to account for publication delays for inflation, we base our investment decision for month $t$ on the interest rates at the start of month $t$ and the (annual) inflation rate in month $t-6$. For many countries, initial estimates of inflation (and output) may become available earlier than six months after the relevant period. However, these first releases often are adjusted substantially in subsequent months. Using a delay of six months avoids the largest part of these revisions. In sum, the real interest differential (RID) rule can be thought of in terms of the variable $R I D_{t}$, defined as

$$
R I D_{t}= \begin{cases}1 & \text { if } i_{t}^{E M}-\pi_{t-6}^{E M}<i_{t}^{U S}-\pi_{t-6}^{U S}, \\ -1 & \text { otherwise }\end{cases}
$$

where $i_{t}^{X}$ is the short-term interest in country $X$ at the start of month $t$ and $\pi_{t-6}^{X}$ is

\footnotetext{
${ }^{10}$ Data on inflation and GDP are taken from the IFS database. The Taiwan data comes from the website of the Taiwanese Central Bank.
} 
the annual inflation rate between $t-18$ and $t-6$. The values 1 and -1 for $R I D_{t}$ correspond to a long position in the US dollar and in the emerging market (EM) currency, respectively, in month $t$.

Second, we use the relative GDP growth rates for forecasting the direction of the future exchange rate movement. As higher GDP growth leads to more attractive investment opportunities the country will attract foreign capital inflows. These flows increase the demand for the currency, which therefore is expected to appreciate. Hence, we take a long position in the emerging market currency if its recent GDP growth was higher than the US GDP growth, and a short position when GDP growth was lower. The GDP buy-sell indicator may thus be defined as

$$
G D P_{t}= \begin{cases}1 & \text { if } \Delta G D P_{t-6}^{E M}<\Delta G D P_{t-6}^{U S} \\ -1 & \text { otherwise }\end{cases}
$$

where $\Delta G D P_{t-6}^{X}$ is the GDP growth rate in country $X$. Again we use a delay of six months to account for publication lags and revisions of initial GDP estimates. In addition, to smooth erratic short-run changes in output, we use annual GDP growth rates in (5).

Although in the following we also consider the strategies based on the $R I D$ and $G D P$ signals individually, we mainly focus on an investor who combines these fundamental signals for making her ultimate decision. Of course, there are many different ways to combine the two pieces of information. Here we take the simple average of the two signals, that is

$$
F_{t}=\left(R I D_{t}+G D P_{t}\right) / 2,
$$

such that the combined fundamentalist signal will be $+1(-1)$ if both signals are negative (positive) on the non-US currency, while a neutral signal (0) is given if the $R I D$ and GDP signal are opposite.

The fundamental buy-sell indicators $R I D_{t}, G D P_{t}$, and $F_{t}$ are used to implement trading strategies with monthly rebalancing. The return of the fundamental strategy based on signal $Y_{t}$ for currency $i, r_{i, t}^{Y}$, is computed as $r_{i, t}^{Y}=Y_{t} \cdot r_{t, i}$, where $r_{i, t}$ is the return on a long position in the US dollar (and thus a short position in the non-US currency) for month $t$. This is a self financed long-short investment strategy, because we will be long in one currency and short in the other currency (although neutral positions are also possible in case of the combined strategy). For this reason we use 
the Sharpe Ratio as the main criterion to evaluate the performance of the strategies, because our returns are excess returns.

The strategies are implemented for all the emerging and developed currencies individually. In addition, we consider the performance of equally-weighted (EW) and volatility-weighted (VW) portfolios. The weights in the latter portfolio are set proportional to the inverse of the ex post volatility of the returns, as measured by the standard deviation over the last 52 weeks. ${ }^{11}$ The use of volatility weighting is based on the idea that in that case each currency contributes an approximately equal amount of risk to the total portfolio risk. By using the volatility over the past 52 weeks we take into account that, especially for the emerging markets, the volatilities vary over time. We acknowledge that the use of the volatility over the past year to weight the currencies entails a specific choice. More advanced weighting schemes using an ex ante volatility measure as well as correlations would, however, put serious limitations on the sample period available for forecast evaluation. Hence, these are left for future research. The return of the equally-weighted and volatility weighted portfolios are computed as

$$
r_{t}^{Y, E W}=\frac{1}{n_{t}} \sum_{i \in \Omega_{t}} r_{i, t}^{Y} \quad \text { and } \quad r_{t}^{Y, V W}=\frac{1}{\sum_{i \in \Omega_{t}} \frac{1}{\sigma_{i, t}}} \sum_{i \in \Omega_{t}} \frac{1}{\sigma_{i, t}} r_{i, t}^{Y}
$$

where $\Omega_{t}$ is the set of available currencies at time $t, n_{t}$ the number of currencies in $\Omega_{t}$ at $t$, and $\sigma_{i, t}$ is the volatility of the returns at time $t$ for country $i$ over the past 52 weeks. Initially we form portfolios for the emerging and developed currencies separately. We also combine these two portfolios on an equally-weighted basis to assess the benefits of diversifying across the two currency markets. The latter is of interest given that currency investors mainly focus on developed markets.

\section{- insert Table 2 about here -}

The results for the fundamental strategies based on the individual $R I D$ and GDP signals are summarized in Table 2. It is seen that for all individual emerging currencies the performance of both fundamental strategies is positive, except for the RID strategy applied to Taiwan, Israel, Romania and Malaysia. For the GDP

\footnotetext{
${ }^{11}$ For the first 12 months of our sample period the volatilities are set equal to the volatility over this first year to avoid losing 12 observations.
} 
strategy the Sharpe ratio is significantly different from zero (in terms of $t$-values at a one-sided $5 \%$ significance level) for nine currencies, while this holds for six currencies for the RID strategy. The GDP strategy seems to perform somewhat better in terms of risk-adjusted returns, as its Sharpe ratio is higher than the RID strategy for 13 of the 21 currencies. Within the strategies the results vary substantially across countries. For example, the average returns on the RID strategy range between 16.79 and -9.17 percent for Turkey and Romania, respectively. Large cross-country differences also show up in the volatilities of the strategies' returns, see India and Indonesia, for example.

For the control sample of developed currencies we find similar results. A difference with the emerging markets is, however, that the real interest rate differential seems to be somewhat more informative for the exchange rate movements than the relative GDP growth rates. The $R I D$ strategy results in positive average returns for all developed currencies, which furthermore are statistically significant for four of the nine countries. The GDP strategy achieves significantly positive Sharpe ratios for two countries only, while in addition the risk-adjusted returns are significantly negative for Canada and Norway.

The results in Table 2 do not take into account transaction costs. To investigate the influence of such costs, we record the number of transactions in each strategy and compute break-even transaction costs. ${ }^{12}$ The average number of transactions per year is equal to approximately 1 and 0.5 for the $R I D$ and GDP strategies, respectively. Compared to trend strategies these numbers are rather low (as shown in the next section), which results in relatively high levels of break-even transaction costs. For most countries and strategies having a positive performance they exceed 2 percent, which for most currencies is clearly above the level of transactions costs encountered in practice by a large institutional investor. ${ }^{13}$

Combining the individual currencies in a portfolio results in positive returns for both fundamental strategies, which are highly significant. For example, the $t$ statistics of the Sharpe ratios for the equally-weighted emerging market portfolios

\footnotetext{
${ }^{12}$ Break-even transaction costs are defined as the strategies average annual return divided by the average number of transactions per year.

${ }^{13}$ More detailed results on the RID and GDP strategies for the individual currencies are not shown here to save space, but are available upon request.
} 
are 2.77 and 3.78 for the $R I D$ and GDP strategies, respectively. The benefits of diversification across currencies become clear by noting the low volatilities of the portfolio returns. For the emerging markets, we also observe a substantial difference in returns for the equally-weighted and volatility-weighted portfolios for both strategies. This is due to the fact that the countries generating the highest average returns for the fundamental strategies, including Turkey, Hungary, Brazil, and Indonesia also have the highest exchange rate volatility (see Table 1) and thus receive a relatively small weight in the volatility-weighted portfolio. The decline in average return when going from equal weighting to volatility weighting is, however, almost compensated by the reduction in volatility, such that the Sharpe ratios decreases only modestly, from 0.86 to 0.63 and from 1.17 to 1.03 for the RID and GDP strategy, respectively. For the developed currencies the return and risk characteristics of the equally-weighted and volatility-weighted portfolios differ much less, due to the fact that the volatilities of these currencies are much more comparable, see again Table 1. Finally, we observe that diversifying across emerging and developed currencies is worthwhile. The loss in return is more than compensated by the large reduction in risk (due to the low correlation of 0.13 between the emerging and developed portfolios), such that the Sharpe ratios of the portfolios that include all currencies exceed those of the portfolios that are limited to either emerging or developed currencies.

\section{- insert Table 3 about here -}

Our next step is to combine the individual fundamental signals, as in (6), which gives results as shown in Table 3. Given that we consider an equally-weighted combination, we know a priori that the mean return of the combined strategy will be equal to the simple average of the mean returns of the RID and GDP strategies. Volatility will be reduced, to an extent that depends directly on the correlation between the returns of the individual strategies. For the emerging currencies, this correlation varies between large negative values of around -0.85 for Argentina and Romania, to fairly large positive values of around 0.70 for Korea, the Philippines and Hungary (leaving the extreme cases of Malaysia and South Africa out of consideration). As a result, the reduction in volatility also differs widely, ranging from a mere 5 percent to no less than 70 percent for the currencies with large positive and negative correlations, respectively. 
The beneficial effects of combining the fundamental signals are in fact more pronounced for the developed currencies. Except for Japan, the correlations between the $R I D$ and GDP strategies are more moderate, not exceeding 0.3, such that volatility is reduced considerably when combining the two. This becomes apparent especially at the portfolio level, where the correlations are around 0.65 for the emerging portfolios, compared to -0.10 for the developed portfolios. Hence, while the reduction in volatility is only about 10 percent for the emerging portfolios, it is considerably larger for the developed portfolios at 25 and 40 percent relative to the $G D P$ - and RID-based portfolios, respectively. As a result, for the emerging portfolios the Sharpe ratio of the combined strategy portfolio is lower than the Sharpe ratio of the GDP-based portfolio. By contrast, for the developed portfolios we find a substantial improvement in the risk-adjusted performance. For example, the Sharpe ratio for the equally-weighted portfolio reaches 1.02 , compared to 0.75 and 0.63 for the corresponding portfolio in the RID and the GDP strategies, respectively.

Finally, we return to the results for the individual emerging currencies. On a risk-adjusted basis the benefits of combining the two fundamental signals may not seem obvious at first sight, given that the Sharpe ratio of the combined strategy is higher than both individual Sharpe ratios for five currencies only. However, we do observe that the performance differences across countries of the combined strategy are much less extreme than for the individual strategies in Table 2. For all 21 currencies except Taiwan and Malaysia we find positive average returns, which are significant for 12 currencies (at the one-sided $5 \%$ level). In sum, combining the RID and GDP signals results in an attractive and fairly robust fundamentalist trading strategy.

\section{Chartist trading strategies}

From the large universe of technical trading rules that is available we implement two specific rules, namely moving average rules and support and resistance rules. Both rules are widely considered in the literature on technical analysis in currency markets.

Moving average $(M A)$ rules are by far the most popular technical trading rules employed by chartists. The general idea of these rules is to give a buy signal when 
a fast moving average of the spot rate over the previous $K$ days is above a slow moving average taken over the previous $L$ days, that is

$$
M A_{t}(K, L)= \begin{cases}1 & \text { if } \frac{1}{K} \sum_{k=1}^{K} S_{t-k} \geq \frac{1}{L} \sum_{l=1}^{L} S_{t-l}, \\ -1 & \text { otherwise }\end{cases}
$$

where $K<L$. Moving average rules are sometimes referred to as trend-following rules, as they generate long (short) signals when the exchange rate has recently been rising (falling). We compute the returns of the moving average strategy as before, with the difference that the signal in (8) is updated daily.

The results of moving average rules are known to be sensitive to the choice of $K$ and $L$. To prevent that our conclusions are based on one specific parameter setting, we decide to combine a range of moving average rules instead of testing one particular rule, see also Okunev and White (2003). To determine a reasonable range for the lengths of the fast and slow moving averages, we vary $K$ between $1-20$ days in steps of one day and $L$ between 25 - 200 days in steps of 5 days. Figure 2 shows the empirical results for the individual moving average strategies based on (8) for each of the resulting 720 different combinations of $K$ and $L$. Panels (a) and (b) of Figure 2 show the average $t$-values for the 21 emerging markets currencies and for the nine developed currencies, respectively. For the emerging markets we observe that the average $t$-value of these strategies is positive for all settings. Furthermore, the average $t$-values are reasonably high (that is, exceeding 1 ) for the rules with a relatively short slow moving average $(L<65)$, independent of the length of the fast moving average.

The trading rule profits for the developed markets are close to zero. For all settings the $t$-value is between -0.5 and 1 . Closer inspection of these results reveals that they actually are poor for each of the individual developed currencies. This finding is in line with Olson (2004), Pukthuanthong-Le et al. (2007) and Neely et al. (in press), who report that profit opportunities for the moving average rules in the developed currency markets disappeared by the mid-1990s.

Based on these results we decide to select all rules with a fast moving average between 5 and 20 days and a slow moving average between 25 and 65 days, resulting in 144 combinations of $K$ and $L$. For the reason of high turnovers, we do not consider short moving averages with $K<5$. The simple average of the resulting 
buy-sell signals $M A_{t}(K, L)$ obtained from (8) is defined as the buy-sell indicator $M A_{t}$.

\section{- insert Figure 2 about here -}

Next to moving average rules, support and resistance $(S \mathscr{E} R)$ rules are also widely used chartist trading strategies. Sometimes the support and resistance rule is referred to as 'trading range breakout' or 'channel rule'. The strategy is based on the general idea that if the exchange rate moves to a new high or low it will continue to move in the direction established. Thus, daily signals are based on a comparison between today's price level with the maximum and minimum price levels over some pre-specified period. If the historical maximum and minimum are computed over the previous $N$ days, the specification of the strategy is as follows:

$$
S \& R_{t}(N)= \begin{cases}1 & \text { if } S_{t}>\max \left(S_{t-1}, \ldots, S_{t-N}\right) \\ -1 & \text { if } S_{t}<\min \left(S_{t-1}, \ldots, S_{t-N}\right) \\ S \& R_{t-1}(N) & \text { otherwise }\end{cases}
$$

The $S \mathscr{B} R$ rule described here somewhat differs from the one described in Sullivan et al. (1999). There the position is held for $k$ days, while here we maintain our position until there is a signal of opposite sign. Our version has much lower turnover and is analogous to the channel trading rule originally introduced by Donchian (1960).

Similar to the moving average rules we again combine a range of support and resistance rules with different lengths of the lookback period. To determine an appropriate range we initially vary $N$ between 5 and 200 in steps of 5 days. For the emerging market currencies short lookback periods (between 5 and 25 days) deliver average Sharpe ratios above 1.5, which then gradually decrease towards values below 0.50 for lookback periods longer than 70 days. Turnover is high for the short lookback periods with more than 15 transactions per year, but this declines rapidly to 6 trades as $N$ increases to 25 or more. For the developed markets the trade strategy riskadjusted profits are much lower with average Sharpe ratios around 0.20, irrespective of the length of the lookback period. Based on the Sharpe ratios and turnover levels we select all rules with lookback period between 25 and 65 days, which corresponds to the settings of the slow moving average in the MA rules. We define our second technical buy-sell indicator $S \& R_{t}$ as the simple average of the signals $S \& R_{t}(N)$ obtained from (9). 
In line with the fundamentalists strategies, our ultimate chartist signal $C_{t}$ is the equally weighted combination of the two technical trading strategies, that is

$$
C_{t}=\left(M A_{t}+S \& R_{t}\right) / 2
$$

resulting in a signal which varies between -1 and +1 , with positive (negative) values meaning that on average the technical indicators point towards a depreciation (appreciation) of the non-US currency. The return on the chartists trading strategies is computed by multiplying the chartist signals $M A_{t}, S \& R_{t}$ and $C_{t}$ with the daily return on a long position in the US dollar.

\section{- insert Table 4 about here -}

Table 4 reports the performance statistics of the two chartist strategies. The moving average strategy renders a positive return for 20 of the 21 currencies, where 12 are significant at the $5 \%$ level. One of the best risk-adjusted results is obtained for Taiwan, with a Sharpe ratio of 1.21 and $t$-statistic of 3.94. This is in line with Lee et al. (2001b), who find that moving average technical trading rules work well for Taiwan over the period 1988-1995. This good performance is in sharp contrast to the poor profits of the fundamentalist strategy for this currency. The high Sharpe ratios for Colombia and Romania are also worth mentioning (1.21 and 1.26), although their floating regime history is shorter than for Taiwan. The only negative return, albeit not significant, is found for the Mexican peso, which is in contrast with the positive results reported by Lee et al. (2001a) for the period 1992-99. Apart from the different sample period, this discrepancy can be explained by the fact that Lee et al. (2001a) do not take into account the interest rate differential in the calculation of the exchange rate returns. As seen in Table 1, with an average of 9.93 percent per year the interest rate differential is far from negligible for the Mexican peso. The support and resistance rule renders a positive return for 19 of the 21 emerging market currencies, of which only two are significant. Again the negative returns are not significant. For the individual countries the support and resistance rules are comparable to the moving average rules although the risk-adjusted returns are somewhat lower. Worth mentioning is the Polish zloty, which has different sign of the Sharpe ratio for the different strategies. 
Combining the individual currencies again achieves a large reduction in risk. The equal-weighted portfolio based on the moving average trading rules has a highly economically and statistically significant Sharpe ratio of 1.14. For the support and resistance trading rule this portfolio has a lower but still significant Sharpe ratio of 0.68. These Sharpe ratios increase to 1.43 and 0.98 respectively, when volatility weighting instead of equal weighting is used. This is due to the fact that the trend following trading strategies in general perform well for the relatively less volatile currencies (e.g. Taiwan, Peru, India), while they perform worse for some of the more volatile currencies (e.g. Mexico and Czech Republic).

Turning to the developed currency portfolio we see that neither the moving average nor the support and resistance rule renders a significant risk-adjusted return. This holds for equally-weighted as well as for volatility-weighted portfolios. Given the profitability of chartist strategies in the emerging currency markets it does not come as a surprise that adding emerging market currencies to the developed currency portfolio leads to a sharp increase (between 0.3 and 0.55) in Sharpe ratios for both chartist strategies.

Table 5 reports the results of the combined chartists strategy $C_{t}$. The mean return of the combined strategy is, of course, again equal to the average of the individual technical trading strategies. Due to the high correlation between the $M A$ - and SER-based returns, as shown in the rightmost column of Table 5, the volatility of the combined strategy is not always lower than the volatility of the individual strategies. Except for the Mexican Peso, all risk-adjusted returns for the emerging market currencies are positive. The highest Sharpe ratios are attained for Taiwan, Colombia and Romania, of which the first two are significant. The high $t$-values on the equally and volatility weighted emerging market portfolios show that the returns on these portfolios are highly significant. The high Sharpe ratios indicate the economic significance. For the developed market currencies the performance is neither economically nor statistically significant.

\section{- insert Table 5 about here -}

Trend models with daily rebalancing as considered here may lead to higher turnover. For that reason we again consider the effects of transactions costs. Columns 6 and 7 in Table 5 show the number of transactions and the break-even transaction 
costs, respectively. Averaged across individual currencies, the number of transactions equals approximately 5.1 per year, which means that the chartist investor trades about once every two and a half months in each currency. Compared to the fundamental strategies these numbers are rather high. For most countries and strategies having a positive performance, break-even transaction costs exceed 0.4 percent, which for most currencies is still above the level of transactions costs encountered in practice by a large institutional investor.

Thus, based on our empirical analysis, we conclude that chartists may benefit from applying moving average and support and resistance trading rules in emerging markets currencies. Note that this is not the case for the developed markets in our control sample. Although the average combined technical trading return is positive for eight of the nine currencies, none of these are significantly different from zero. Even combining the currencies into a portfolio does not render significantly positive risk-adjusted returns, possibly as a result of the limited diversification potential due to the high cross-correlations among these currencies.

\section{Combining fundamentalist and chartist trading strategies}

In the previous two sections we analyzed the profitability of fundamentalist and chartist investment strategies for emerging currency markets. Our empirical results indicate that both types of strategies generate significantly positive risk-adjusted returns over the period 1997-2007. In this section, we investigate whether the performance can be further improved by combining fundamental and technical information. We start by examining a naive equally-weighted combination of both types of information. Subsequently, we extend this to a combined strategy where the relative weight given to fundamental and chartist signals is based on their past performance.

Table 6 shows the performance statistics of the strategy that is based on an equally-weighted combination of the fundamental signal $F_{t}$ and the chartist signal $C_{t}$. This strategy mimics the behavior of a currency trader who puts equal value on fundamentalist and chartist information. The benefits of combining both sources of information is clearly borne out by the results for the individual emerging markets. The 'naive' combination yields positive risk-adjusted returns for all 21 currencies, 
with no less than 14 being significant at the $5 \%$ level. We also note that turnover is reduced compared to the chartist strategy in Table 5, such that for most currencies the break-even transaction costs are considerably higher than transaction cost levels encountered in practice.

At the portfolio level, the highly significant Sharpe ratios equal 1.36 and 1.50 for the equally-weighted and volatility-weighted portfolios, respectively. The Sharpe ratio of the combined strategy is significantly higher than both Sharpe ratios of the fundamental and chartist strategies individually according to the Jobson and Korkie (1981) test (and Memmel's (2003) adjustment). ${ }^{14}$ This indicates that over the past decade an emerging markets currency trader would have earned higher risk-adjusted returns from combining fundamentalist and chartist trading rules, even with a naive equally-weighted combination.

\section{- insert Table 6 about here -}

This result for emerging markets is in line with the questionnaire results obtained by Taylor and Allen (1992), Lui and Mole (1998), Cheung and Chinn (2001), and Gehrig and Menkhoff (2004), which indicate that foreign exchange dealers, based in the major foreign exchange trading centers, view technical and fundamental analysis as complementary sources of information. In contrast, a naive combination does not seem to add sufficient value for an investor in the developed markets. We observe that the euro and Japanese yen are the only individual developed currencies having a risk-adjusted return that is statistically significant at the $5 \%$ level. The Sharpe ratio is even negative (albeit insignificant) for Great-Britain. The equally-weighted and volatility-weighted portfolios of developed currencies yield $t$-values of the Sharpe ratios of 2.08 and 2.13, respectively, indicating that the risk-adjusted returns $(0.64$ and 0.66) are significantly different from zero.

Finally, we observe that the combined strategy with developed and emerging markets currencies leads to higher risk-adjusted returns than that of developed markets alone. This improvement comes from a higher return and a lower volatility. For

\footnotetext{
${ }^{14}$ Comparing the Sharpe ratios of the combined strategy with the fundamentalist strategy we obtain Jobson-Korkie $t$-values of 2.69 and 6.51 for the equally weighted and volatility weighted portfolios, respectively. In the comparison of the combined strategy with the chartist strategy, the corresponding $t$-values are 3.99 and 2.22 .
} 
example, the return increases from 2.04 to 3.15 percent, while the volatility decreases from 3.18 to 2.48 for the equal weighted portfolio. We see the same effect for the volatility weighted portfolio. This suggests that extending a developed investment universe with emerging markets is beneficial for currency managers.

In the heterogeneous agents models developed in Chiarella et al. (2006), De Grauwe and Grimaldi (2005, 2006) and De Grauwe and Markiewicz (2006), agents determine the weights assigned to the different available investment strategies based on their relative past performance. In order to test whether this type of strategy delivers superior returns we consider a combined investment strategy with monthly rebalancing and dynamic weights placed on fundamental and chartist signals as follows:

$$
\begin{aligned}
W_{t}^{F} & =\frac{\exp \left(\gamma \sum_{j=1}^{J} r_{t-j}^{F}\right)}{\exp \left(\gamma \sum_{j=1}^{J} r_{t-j}^{F}\right)+\exp \left(\gamma \sum_{j=1}^{J} r_{t-j}^{C}\right)}, \\
W_{t}^{C} & =\frac{\exp \left(\gamma \sum_{j=1}^{J} r_{t-j}^{C}\right)}{\exp \left(\gamma \sum_{j=1}^{J} r_{t-j}^{F}\right)+\exp \left(\gamma \sum_{j=1}^{J} r_{t-j}^{C}\right)}=1-W_{t}^{F},
\end{aligned}
$$

where $W_{t}^{F}$ and $W_{t}^{C}$ are the weights on the fundamentalist and chartist signals, respectively, $r_{t}^{F}$ and $r_{t}^{C}$ are the returns on the fundamentalist and chartist trading strategies in month $t$, and $J$ is the length of the look-back period of the investor. The parameter $\gamma \geq 0$ determines the strength of the deviation from the equally weighted average and thus measures the 'aggressiveness' of the dynamic weighting scheme. Note that the limiting case $\gamma=0$ implies equal weighting, as this reduces $W_{t}^{F}$ and $W_{t}^{C}$ to 0.5 . Figure 3 shows an example of the sensitivity of the dynamic weights, with $J=12$ months, for the choice of $\gamma$ for Korea over the period 2004-2007.

\section{- insert Figure 3 about here -}

In Figure 4 we display the results from the dynamic weighting scheme in (11) and (12) over the period 1999-2007. ${ }^{15}$ This figure shows the Sharpe ratios of the portfolio based on the combined strategy with dynamic weights for different look-back periods $J$ ranging from 1 to 24 months and for different levels of 'aggressiveness' as measured

\footnotetext{
${ }^{15}$ We reduce the sample period to $1999-2007$ such that the performance evaluation covers the same period for all values of the look-back period $J$, which we vary between 1 and 24 months.
} 
by $\gamma$. Panel (a) of Figure 4 contains the results for the emerging markets portfolio. We observe a gradual increase in the Sharpe ratio when the look-back period gets longer and the strategy becomes more aggressive, reaching a maximum of 1.60 for $J=24$ and $\gamma=50$. Although the Sharpe ratio improvements with the dynamic weighting scheme are statistically significant for some combinations of $J$ and $\gamma$, this result does not seem to be robust. ${ }^{16}$ In panel (b) of Figure 4, where we rotate the graph by 90 degrees, it can be seen that for developed currency markets the naive equally-weighted combination seems to be as good as any dynamic strategy within the range of parameters considered. The differences in Sharpe ratios are not statistically significant.

\section{- insert Figure 4 about here -}

In addition to Figure 4, in which the Sharpe ratios at the portfolio level are shown for the complete range of values considered for $J$ and $\gamma$, we display the results for one particular combination ( $J=12$ months and $\gamma=30$ ) for illustrative purposes in Table 7. The results from this dynamic approach are mixed for the individual countries, as about three-quarters of the Sharpe ratios (and their $t$-values) decrease relative to the equally-weighted strategy. Nevertheless, we observe an increase in the level of riskadjusted returns for both emerging market portfolios from 1.12 and 1.41 to 1.27 and 1.48 for the equally-weighted and volatility-weighted portfolios, respectively. Taken together, these results lead us to the conclusion that a dynamic weighting scheme between chartists and fundamentalists may yield improved performance relative to an equally weighted combination, but this is sensitive to the length of the lookback period $J$ and the level of aggressiveness $\gamma$. However, the main conclusion from this section is that combining chartist and fundamentalist's information is profitable in emerging currency markets.

\section{- insert Table 7 about here -}

\section{Conclusions}

Empirical research on exchange rate forecasting has tended to focus on the usefulness of either technical analysis or of structural exchange rate models. Both question-

\footnotetext{
${ }^{16}$ More detailed results are available upon request.
} 
naires among foreign exchange market participants as well as recently developed heterogeneous agents models indicate that both types of information are relevant for assessing future exchange rate movements. In addition, the heterogeneous agents models suggest that the relative importance of chartism and fundamentalism varies over time according to the past performance of the corresponding trading strategies.

In this paper we analyze the economic value of combining chartist and fundamentalist information for 21 emerging currency markets with a floating exchange rate regime over the period 1997-2007. We use the appropriate historical NDF data for the 14 currencies in our sample which have or had trading restrictions on foreign capital movements. We document that a combined chartist/fundamentalist investment strategy renders economically and statistically significant positive risk-adjusted returns. Although both fundamentalist and chartist trading rules individually also generate positive risk-adjusted returns on average, the performance of the combined strategy is far superior and, in particular, much more stable across countries. We find only limited evidence that a dynamic strategy, in which the weights assigned to chartist and fundamental information are adjusted dynamically based on relative past performance, outperforms a naive equally-weighted combination.

Further research can be done on the inclusion of other types of information in the emerging currency market. In particular, it may be of interest to expand our information set with information on (proprietary) customer order flows of investment banks, which have been studied, as far as our knowledge, only for developed markets, see Evans and Lyons (1999), among others. Gehrig and Menkhoff (2004), for example, document that many foreign exchange market participants consider flow analysis as an independent third type of information, next to technical analysis and fundamental information. The inclusion of this additional source of information may further increase the economic value of emerging markets currency investments. Another potential avenue for further research would be to investigate other statistical techniques to combine fundamental and chartist information dynamically, although it is likely that these methods require a larger number of observations than currently available for emerging markets. Bayesian Model Averaging, for example applied by Wright (2003) and Garratt and Lee (2007) for the developed currency markets, can be one of these methods. 


\section{References}

Abhyankar, A., L. Sarno, and G. Valente (2005), Exchange rates and fundamentals: evidence on the economic value of predictability, Journal of International Economics, 66, 325-348.

Berkowitz, J. and L. Giorgianni (2001), Long-horizon exchange rate predictability, Review of Economics and Statistics, 83, 81-91.

Brock, W. and C. Hommes (1997), A rational route to randomness, Econometrica, 65, 1059-1095.

Brock, W. and C. Hommes (1998), Heterogeneous beliefs and routes to chaos in a simple asset pricing model, Journal of Economic Dynamics and Control, 22, $1235-1274$.

Candelon, B. and S. Straetmans (2006), Testing for multiple regimes in the tail behavior of emerging currency returns, Journal of International Money and Finance, 25, 1187-1205.

Cheung, Y.-W. and M. D. Chinn (2001), Currency traders and exchange rate dynamics: a survey of the US market, Journal of International Money and Finance, 20, 439-471.

Cheung, Y.-W., M. D. Chinn, and A. G. Pascual (2005), Empirical exchange rate models of the nineties: are any fit to survive?, Journal of International Money and Finance, 24, 1150-1175.

Chiarella, C., X.-Z. He, and C. Hommes (2006), A dynamic analysis of moving average rules, Journal of Economic Dynamics and Control, 30, 1729-1753.

De Grauwe, P. and M. Grimaldi (2005), Heterogeneity of agents, transactions costs, and the exchange rate, Journal of Economic Dynamics and Control, 29, 691-719.

De Grauwe, P. and M. Grimaldi (2006), Exchange rate puzzles: a tale of switching attractors, European Economic Review, 50, 1-33.

De Grauwe, P. and A. Markiewicz (2006), Learning to forecast the exchange rate: Two competing approaches, CESifo Working Paper No. 1717. 
De Jong, E., W. F. Verschoor, and R. C. J. Zwinkels (2006), Heterogeneity of agents and excange rate dynamics: evidence from the EMS, Radboud University, working paper.

Donchian, R. D. (1960), High finance in copper, Financial Analysts Journal, 16, $133-142$.

Evans, M. and R. K. Lyons (1999), Order flow and exchange rate dynamics, Journal of Political Economy, 110, 170-180.

Frankel, J. A. (1979), On the Mark: a theory of floating exchange rates based on real interest differentials, American Economic Review, 69, 610-622.

Frankel, J. A. and K. A. Froot (1990), Chartists, fundamentalists, and trading in the foreign exchange market, American Economic Review, 80, 181-185.

Garratt, A. and K. Lee (2007), Investing under model uncertainty: decision based evaluation of exchange rate forecasts in the US, UK and Japan, Birkbeck College, working paper.

Gehrig, T. and L. Menkhoff (2004), The use of flow analysis in foreign exchange: exploratory evidence, Journal of International Money and Finance, 23, 573-594.

Isaac, A. G. and S. de Mel (2001), The real-interest-differential model after 20 years, Journal of International Money and Finance, 20, 473-495.

Jobson, J. and B. Korkie (1981), Performance hypothesis testing with the Sharpe and Treynor measures, Journal of Finance, 36, 889-908.

Kaminsky, G. L. (2006), Currency crisis: are they all the same?, Journal of International Money and Finance, 25, 503-527.

Kilian, L. (2001), Exchange rates and fundamentals: What do we learn from longhorizon regressions?, Journal of Applied Econometrics, 14, 491-510.

LeBaron, B. (1999), Technical trading rule profitability and foreign exchange intervention, Journal of International Economics, 49, 125-143. 
Lee, C. I., K. C. Gleason, and I. Mathur (2001a), Trading rule profits in Latin American currency spot rates, International Review of Financial Analysis, 10, $135-156$.

Lee, C. I., M.-S. Pan, and Y. A. Liu (2001b), On market efficiency of Asian foreign exchange rates: Evidence from a joint variance ratio test and technical trading rules, Journal of International Financial Markets, Institutions and Money, 11, 199-214.

Leitch, G. and J. E. Tanner (1991), Economic forecast evaluation: profits versus the conventional error measures, American Economic Review, 81, 580-590.

Levich, R. and L. Thomas (1993), The significance of technical trading rule profits in the foreign exchange market: a bootstrap approach, Journal of International Money and Finance, 12, 451-474.

Lipscomb, L. (2005), An overview of non-deliverable foreign exchange forward markets, Federal Reserve Bank New York.

Lui, Y. and D. Mole (1998), The use of fundamental and technical analyses by foreign exchange dealers: Hong Kong evidence, Journal of International Money and Finance, 17, 535-545.

Mark, N. C. (1995), Exchange rates and fundamentals: Evidence on long-horizon predictability, American Economic Review, 85, 201-218.

Martin, A. D. (2001), Technical trading rules in the spot foreign exchange markets of developing countries, Journal of Multinational Financial Management, 11, 59-68.

McNown, R. and M. Wallace (1989), National price levels, purchasing power parity, and cointegration: a test of four high inflation economies, Journal of International Money and Finance, 8, 533-545.

Meese, R. and K. Rogoff (1983), Empirical exchange rate models of the seventies: do they fit out-of-sample?, Journal of International Economics, 14, 3-24.

Memmel, C. (2003), Performance hypothesis testing with the Sharpe ratio, Finance Letters, 1, 21-23. 
Menkhoff, L. (1997), Examining the use of technical currency analysis, Journal of Economic Literature, 2, 307-318.

Menkhoff, L. and M. P. Taylor (2007), The obstinate passion of foreign exchange professionals: Technical analysis, Journal of Economic Literature, 45, 936-972.

Neely, C. J. and P. A. Weller (1999), Technical trading rules in the European Monetary System, Journal of International Money and Finance, 18, 429-458.

Neely, C. J., P. A. Weller, and J. M. Ulrich (in press), The adaptive markets hypothesis: evidence from the foreign exchange market, Journal of Financial and Quantitative Analysis.

Okunev, J. and D. White (2003), Do momentum-based strategies still work in foreign currency markets?, Journal of Financial and Quantitative Analysis, 38, 425-447.

Olson, D. (2004), Have trading rule profits in the currency markets declined over time?, Journal of Banking and Finance, 28, 85-105.

Park, C.-H. and S. H. Irwin (2007), What do we know about the profitability of technical analysis?, Journal of Economic Surveys, 21, 786-826.

Pukthuanthong-Le, K., R. M. Levich, and L. R. Thomas (2007), Do foreign exchange markets still trend?, Journal of Portfolio Management, 34, 114-118.

Sullivan, R., A. Timmermann, and H. White (1999), Data-snooping, technical trading rule performance and the bootstrap, Journal of Finance, 54, 1647-1691.

Sweeney, R. (1986), Beating the foreign exchange market, Journal of Finance, 41, $163-182$.

Taylor, M. P. and H. Allen (1992), The use of technical analysis in the foreign exchange market, Journal of International Money and Finance, 11, 304-314.

Vigfusson, R. (1997), Switching between chartists and fundamentalists: a Markov regime-switching approach, International Journal of Financial Economics, 2, 291305.

Wright, J. (2003), Bayesian Model Averaging and exchange rate forecasts, International Finance Discussion Paper 779, Federal Reserve Board of Governors. 
Table 1: Summary statistics currency returns

\begin{tabular}{|c|c|c|c|c|c|c|c|c|}
\hline Currency & Forward & Float & Mean & Stdev & Skew. & Kurt. & FX & IRD \\
\hline \multicolumn{9}{|l|}{ Emerging } \\
\hline Taiwanese dollar (TWD) & ND & Dec-96 & 1.62 & 5.68 & -0.10 & 5.38 & 1.7 & 0.0 \\
\hline Peruvian sol $(\mathrm{PEN})^{*}$ & ND & Dec-96 & -4.17 & 3.51 & -0.52 & 2.58 & -1.3 & -2.9 \\
\hline Indian rupee (INR) & ND & Dec-96 & -5.13 & 4.36 & 0.33 & 4.57 & 1.2 & -6.3 \\
\hline Mexican peso (MXN) & $\mathrm{D}$ & Dec-96 & -6.93 & 8.42 & 0.76 & 2.39 & 3.0 & -9.9 \\
\hline South African rand (ZAR) & $\mathrm{D}$ & Dec-96 & -3.48 & 15.94 & 0.21 & 1.02 & 3.9 & -7.4 \\
\hline Czech koruna (CZK) & $\mathrm{D}$ & May-97 & -5.45 & 11.57 & -0.27 & -0.20 & -4.5 & -1.0 \\
\hline Israeli shekel (ILS) ${ }^{* *}$ & $\mathrm{D}$ & Jun-97 & -1.57 & 7.40 & 1.45 & 5.45 & 1.9 & -3.5 \\
\hline Thai baht $(\mathrm{THB})^{* *}$ & $\mathrm{D}$ & Jul-97 & -5.68 & 11.93 & -2.43 & 17.75 & -3.3 & -2.4 \\
\hline Philippine peso (PHP) & ND & Jul-97 & -6.85 & 8.79 & -0.64 & 5.40 & 1.4 & -8.3 \\
\hline Indonesian rupiah (IDR)** & ND & Aug-97 & -12.54 & 26.41 & -0.66 & 8.98 & 0.4 & -12.9 \\
\hline Korean won (KRW) & ND & Dec-97 & -7.11 & 9.82 & -0.49 & 5.25 & -4.6 & -2.5 \\
\hline Slovak koruna (SKK) & $\mathrm{D}$ & Oct-98 & -9.02 & 10.28 & -0.24 & -0.29 & -6.2 & -2.8 \\
\hline Brazilian real (BRL) & ND & Feb-99 & -11.87 & 17.43 & 1.26 & 6.11 & 0.9 & -12.8 \\
\hline Chilean peso (CLP) & ND & Sep-99 & -0.74 & 9.13 & -0.10 & -0.30 & 0.7 & -1.4 \\
\hline Colombian peso (COP) & ND & Sep-99 & -5.24 & 9.22 & -0.08 & 3.14 & 0.1 & -5.3 \\
\hline Polish zloty (PLN) & $\mathrm{D}$ & Apr-00 & -11.92 & 11.01 & 0.08 & -0.30 & -7.1 & -4.8 \\
\hline Turkish lira (TRY) & $\mathrm{D}$ & Feb-01 & -29.23 & 16.87 & 0.28 & 2.01 & -0.2 & -29.0 \\
\hline Hungarian forint (HUF) & $\mathrm{D}$ & May-01 & -13.66 & 12.05 & 0.58 & 1.17 & -7.7 & -5.9 \\
\hline Argentine peso (ARS) & ND & Jan-02 & -17.49 & 12.25 & -2.61 & 9.46 & -4.1 & -13.3 \\
\hline Romanian leu $(\mathrm{RON})^{* *}$ & $\mathrm{D}$ & Oct-04 & -10.75 & 8.77 & 0.15 & -0.94 & -8.0 & -2.8 \\
\hline Malaysian ringitt (MYR) & ND & Jul-05 & -3.76 & 3.48 & 0.43 & 0.08 & -6.0 & 2.2 \\
\hline \multicolumn{9}{|l|}{ Developed } \\
\hline$\overline{\text { Australian dollar (AUD) }}$ & $\mathrm{D}$ & Dec-96 & -1.78 & 10.34 & 0.17 & -0.22 & -0.6 & -1.2 \\
\hline Canadian dollar (CAD) & $\mathrm{D}$ & Dec-96 & -2.17 & 6.65 & -0.06 & -0.19 & -2.4 & 0.3 \\
\hline UK Sterling (GBP) & $\mathrm{D}$ & Dec-96 & -2.81 & 7.38 & 0.01 & -0.17 & -1.6 & -1.2 \\
\hline Japanese yen (JPY) & $\mathrm{D}$ & Dec-96 & 4.44 & 10.95 & -1.17 & 4.72 & 0.6 & 3.9 \\
\hline Euro (EUR) & $\mathrm{D}$ & Dec-96 & 0.30 & 9.47 & -0.31 & -0.03 & -0.6 & 0.9 \\
\hline Swiss franc $(\mathrm{CHF})$ & $\mathrm{D}$ & Dec-96 & 1.72 & 9.65 & -0.32 & -0.41 & -0.9 & 2.6 \\
\hline Norwegian krone (NOK) & $\mathrm{D}$ & Dec-96 & -1.45 & 10.39 & -0.12 & 0.43 & -0.8 & -0.6 \\
\hline Swedish krone (SEK) & $\mathrm{D}$ & Dec-96 & 0.65 & 10.22 & -0.34 & 0.12 & 0.0 & 0.7 \\
\hline N. Zealand dollar (NZD) & $\mathrm{D}$ & Dec-96 & -3.03 & 11.21 & 0.22 & 0.10 & -0.8 & -2.2 \\
\hline
\end{tabular}

Note: The table shows annualized statistics (mean, standard deviation, skewness and kurtosis) of monthly returns on 21 emerging markets and 9 developed market foreign exchange rates (based on a long US dollar position and a short position in the emerging market) for the period January 1997 June 2007. The returns include the spot rate change as well as the interest rate differential between the US and the specific country. The column headed 'Float' shows the start date of the currencies' floats (where Dec-96 indicates that the currency already was floating at the start of the sample period), while the column headed 'Forward' indicates the type of forward contracts available for a speculative investor: deliverable (D) or non-deliverable (ND). The two rightmost columns report the average annualized return on the foreign exchange rate (FX) and the average annualized interest rate differential (IRD), respectively.

* The Peruvian sol became tradable in Nov-99 and is included in our sample thereafter.

** Capital controls were introduced for the Indonesian rupiah in 2000 and Thai bath in 2007. Prior to these dates their currency forwards were deliverable. In contrast the Israeli shekel (deliverable since 1998) and the Romanian leu (deliverable since 2005) started trading in the NDF market. 
Table 2: Performance of fundamental trading strategies

\begin{tabular}{|c|c|c|c|c|c|c|c|c|}
\hline & \multicolumn{4}{|c|}{$R I D$} & \multicolumn{4}{|c|}{$G D P$} \\
\hline & Mean & Stdev & Sharpe & $t$-value & Mean & Stdev & Sharpe & $t$-value \\
\hline \multicolumn{9}{|l|}{ Emerging } \\
\hline TWD & -1.25 & 5.69 & -0.22 & -0.71 & 0.68 & 5.70 & 0.12 & 0.39 \\
\hline PEN & 2.91 & 3.63 & 0.80 & 2.20 & 1.15 & 3.69 & 0.31 & 0.86 \\
\hline INR & 0.71 & 4.61 & 0.15 & 0.50 & 5.13 & 4.36 & 1.18 & 3.81 \\
\hline MXN & 3.52 & 8.60 & 0.41 & 1.33 & 6.99 & 8.42 & 0.83 & 2.69 \\
\hline ZAR & 3.94 & 15.93 & 0.25 & 0.80 & 5.05 & 15.91 & 0.32 & 1.03 \\
\hline CZK & 3.92 & 11.62 & 0.34 & 1.05 & 5.78 & 11.56 & 0.50 & 1.55 \\
\hline ILS & -0.10 & 7.42 & -0.01 & -0.04 & 1.28 & 7.41 & 0.17 & 0.53 \\
\hline THB & 5.44 & 11.94 & 0.46 & 1.40 & 1.95 & 12.03 & 0.16 & 0.50 \\
\hline PHP & 2.53 & 8.98 & 0.28 & 0.87 & 6.85 & 8.79 & 0.78 & 2.40 \\
\hline IDR & 8.32 & 26.55 & 0.31 & 0.96 & 13.82 & 26.36 & 0.52 & 1.60 \\
\hline KRW & 2.70 & 10.00 & 0.27 & 0.81 & 2.86 & 10.00 & 0.29 & 0.86 \\
\hline SKK & 2.81 & 10.58 & 0.27 & 0.76 & 6.49 & 10.44 & 0.62 & 1.79 \\
\hline BRL & 12.30 & 17.40 & 0.71 & 1.99 & 10.39 & 17.51 & 0.59 & 1.67 \\
\hline CLP & 1.34 & 9.12 & 0.15 & 0.40 & 1.15 & 9.13 & 0.13 & 0.34 \\
\hline $\mathrm{COP}$ & 10.92 & 8.79 & 1.24 & 3.36 & 3.81 & 9.28 & 0.41 & 1.11 \\
\hline PLN & 9.95 & 11.18 & 0.89 & 2.31 & 9.96 & 11.17 & 0.89 & 2.32 \\
\hline TRY & 16.79 & 18.25 & 0.92 & 2.24 & 29.23 & 16.87 & 1.73 & 4.21 \\
\hline HUF & 12.78 & 12.13 & 1.05 & 2.51 & 12.24 & 12.18 & 1.00 & 2.39 \\
\hline ARS & 3.95 & 13.22 & 0.30 & 0.67 & 0.41 & 13.27 & 0.03 & 0.07 \\
\hline $\mathrm{RON}$ & -9.17 & 8.92 & -1.03 & -1.51 & 10.75 & 8.77 & 1.23 & 1.80 \\
\hline MYR & -3.76 & 3.48 & -1.08 & -1.32 & 3.76 & 3.48 & 1.08 & 1.32 \\
\hline \multicolumn{9}{|l|}{ Developed } \\
\hline$\overline{\text { AUD }}$ & 1.35 & 10.35 & 0.13 & 0.42 & 9.05 & 10.02 & 0.90 & 2.93 \\
\hline CAD & 3.28 & 6.62 & 0.50 & 1.61 & -3.43 & 6.61 & -0.52 & -1.68 \\
\hline GBP & 1.63 & 7.41 & 0.22 & 0.71 & 1.77 & 7.40 & 0.24 & 0.78 \\
\hline JPY & 6.42 & 10.87 & 0.59 & 1.92 & 4.44 & 10.95 & 0.41 & 1.31 \\
\hline EUR & 7.52 & 9.21 & 0.82 & 2.64 & 5.13 & 9.35 & 0.55 & 1.78 \\
\hline $\mathrm{CHF}$ & 5.44 & 9.53 & 0.57 & 1.85 & 1.62 & 9.65 & 0.17 & 0.54 \\
\hline NOK & 6.42 & 10.23 & 0.63 & 2.03 & -6.72 & 10.21 & -0.66 & -2.13 \\
\hline SEK & 0.00 & 10.23 & 0.00 & 0.00 & 1.62 & 10.21 & 0.16 & 0.52 \\
\hline NZD & 1.08 & 11.24 & 0.10 & 0.31 & 8.19 & 10.99 & 0.75 & 2.41 \\
\hline \multicolumn{9}{|c|}{ Portfolios - equally weighted } \\
\hline$\overline{\mathrm{EM}}$ & 4.09 & 4.78 & 0.86 & 2.77 & 5.55 & 4.76 & 1.17 & 3.78 \\
\hline DEV & 3.68 & 4.89 & 0.75 & 2.44 & 2.41 & 3.85 & 0.63 & 2.03 \\
\hline ALL & 3.89 & 3.80 & 1.02 & 3.32 & 3.98 & 2.87 & 1.39 & 4.49 \\
\hline \multicolumn{9}{|c|}{ Portfolios - volatility weighted } \\
\hline$\overline{\mathrm{EM}}$ & 2.19 & 3.46 & 0.63 & 2.05 & 3.57 & 3.47 & 1.03 & 3.34 \\
\hline DEV & 3.68 & 4.70 & 0.78 & 2.54 & 2.20 & 3.64 & 0.60 & 1.95 \\
\hline ALL & 2.94 & 3.26 & 0.90 & 2.92 & 2.88 & 2.38 & 1.21 & 3.93 \\
\hline
\end{tabular}

Note: The table shows the average return (in annualized percentage points), standard deviation, the Sharpe ratio and its $t$-value for the fundamental strategies based on the real interest differential $(R I D)$ and relative GDP growth $(G D P)$ applied to all exchange rates over their floating currency regime periods (see Table 1 ). The six bottom lines report the same statistics for equally-weighted and volatility-weighted portfolios for emerging markets (EM), for developed markets (DEV), and for all markets (ALL). 
Table 3: Performance of combined fundamentalist trading strategy

\begin{tabular}{lrrrrrrr}
\hline \hline & Mean & Stdev & Sharpe & t-value & \#TR & BETC & CORR \\
\hline Emerging & & & & & & & \\
TWD & -0.29 & 4.88 & -0.06 & -0.19 & 1.43 & -0.1 & 0.47 \\
PEN & 2.07 & 2.62 & 0.79 & 2.17 & 1.05 & 1.0 & 0.02 \\
INR & 2.95 & 3.77 & 0.78 & 2.54 & 1.00 & 1.5 & 0.42 \\
MXN & 5.26 & 7.50 & 0.70 & 2.27 & 0.43 & 6.1 & 0.55 \\
ZAR & 4.49 & 15.69 & 0.29 & 0.93 & 0.29 & 7.9 & 0.94 \\
CZK & 4.85 & 7.80 & 0.62 & 1.93 & 1.09 & 2.2 & -0.10 \\
ILS & 0.59 & 5.87 & 0.10 & 0.31 & 0.89 & 0.3 & 0.26 \\
THB & 3.69 & 4.68 & 0.79 & 2.43 & 1.11 & 1.7 & -0.70 \\
PHP & 4.69 & 8.33 & 0.56 & 1.73 & 0.26 & 8.9 & 0.76 \\
IDR & 11.07 & 23.46 & 0.47 & 1.44 & 0.48 & 11.5 & 0.57 \\
KRW & 2.78 & 9.42 & 0.30 & 0.89 & 1.10 & 1.3 & 0.77 \\
SKK & 4.65 & 7.52 & 0.62 & 1.78 & 0.55 & 4.3 & 0.02 \\
BRL & 11.34 & 14.94 & 0.76 & 2.14 & 0.44 & 12.8 & 0.47 \\
CLP & 1.25 & 8.09 & 0.15 & 0.42 & 1.02 & 0.6 & 0.57 \\
COP & 7.37 & 6.55 & 1.12 & 3.04 & 1.36 & 2.7 & 0.05 \\
PLN & 9.96 & 8.65 & 1.15 & 2.99 & 0.81 & 6.1 & 0.20 \\
TRY & 23.01 & 15.58 & 1.48 & 3.59 & 0.34 & 34.0 & 0.57 \\
HUF & 12.51 & 11.11 & 1.13 & 2.68 & 0.44 & 14.2 & 0.67 \\
ARS & 2.18 & 3.83 & 0.57 & 1.27 & 0.80 & 1.4 & -0.83 \\
RON & 0.79 & 2.43 & 0.32 & 0.48 & 0.46 & 0.9 & -0.85 \\
MYR & 0.00 & NA & NA & NA & 0.00 & NA & -1.00 \\
Developed & & & & & & & \\
\hline AUD & 5.20 & 7.52 & 0.69 & 2.24 & 1.29 & 2.0 & 0.09 \\
CAD & -0.07 & 3.37 & -0.02 & -0.07 & 1.33 & 0.0 & -0.48 \\
GBP & 1.70 & 5.70 & 0.30 & 0.97 & 0.90 & 0.9 & 0.18 \\
JPY & 5.43 & 9.50 & 0.57 & 1.85 & 0.29 & 9.5 & 0.52 \\
EUR & 6.32 & 6.90 & 0.92 & 2.97 & 0.48 & 6.6 & 0.11 \\
CHF & 3.53 & 7.75 & 0.46 & 1.48 & 0.38 & 4.6 & 0.31 \\
NOK & -0.15 & 5.70 & -0.03 & -0.09 & 1.10 & -0.1 & -0.38 \\
SEK & 0.81 & 5.73 & 0.14 & 0.46 & 1.33 & 0.3 & -0.37 \\
NZD & 4.63 & 8.34 & 0.56 & 1.80 & 0.48 & 4.9 & 0.13 \\
Portfolios - equally weighted & & & & & \\
EM & 4.82 & 4.29 & 1.12 & 3.64 & 0.76 & 3.2 & 0.62 \\
DEV & 3.05 & 3.00 & 1.02 & 3.30 & 0.84 & 1.8 & -0.08 \\
ALL & 3.93 & 2.77 & 1.42 & 4.60 & 0.80 & 2.5 & 0.37 \\
Portfolios - volatility & weighted & & & & & \\
EM & 2.88 & 3.16 & 0.91 & 2.96 & 0.49 & 2.9 & 0.66 \\
DEV & 2.94 & 2.76 & 1.06 & 3.45 & 0.61 & 2.4 & -0.14 \\
ALL & 2.91 & 2.24 & 1.30 & 4.22 & 0.55 & 2.6 & 0.24 \\
\hline
\end{tabular}

Note: The table shows the mean return (in annualized percentage points), standard deviation, the Sharpe ratio and its $t$-value, the average number of transactions per year (\#TR) and the breakeven transaction costs (BETC) for the fundamental strategy combining signals from the real interest differential $(R I D)$ and relative GDP growth $(G D P)$, applied to all exchange rates over their floating currency regime periods (see Table 1). The last column (CORR) report the correlation between the returns of the two individual fundamental trading strategies. Transactions (\#TR) are reported as the single counted average number of transactions per year; therefore turnover is twice the number of transactions. Break-even transaction costs (BETC) are defined as the strategies average annual return divided by the average number of transactions per year. 
Table 4: Performance of chartist trading strategies

\begin{tabular}{|c|c|c|c|c|c|c|c|c|}
\hline & \multicolumn{4}{|c|}{$M A$} & \multicolumn{4}{|c|}{$S E R R$} \\
\hline & Mean & Stdev & Sharpe & $t$-value & Mean & Stdev & Sharpe & $t$-value \\
\hline \multicolumn{9}{|l|}{ Emerging } \\
\hline TWD & 4.85 & 4.01 & 1.21 & 3.94 & 4.40 & 4.58 & 0.96 & 3.13 \\
\hline PEN & 1.80 & 2.91 & 0.62 & 1.72 & 1.27 & 2.69 & 0.47 & 1.31 \\
\hline INR & 2.58 & 4.24 & 0.61 & 1.98 & 2.14 & 4.32 & 0.49 & 1.61 \\
\hline MXN & -3.89 & 9.77 & -0.40 & -1.30 & -4.70 & 9.58 & -0.49 & -1.60 \\
\hline ZAR & 6.21 & 13.56 & 0.46 & 1.49 & 0.76 & 14.60 & 0.05 & 0.17 \\
\hline CZK & 1.14 & 10.97 & 0.10 & 0.32 & 2.65 & 10.28 & 0.26 & 0.80 \\
\hline ILS & 4.92 & 5.89 & 0.83 & 2.58 & 1.62 & 6.28 & 0.26 & 0.80 \\
\hline THB & 6.14 & 7.75 & 0.79 & 2.44 & 3.12 & 9.50 & 0.33 & 1.01 \\
\hline PHP & 3.12 & 6.32 & 0.49 & 1.52 & 0.69 & 6.78 & 0.10 & 0.31 \\
\hline IDR & 14.13 & 21.45 & 0.66 & 2.02 & 9.33 & 20.74 & 0.45 & 1.38 \\
\hline KRW & 4.82 & 7.96 & 0.61 & 1.82 & 2.29 & 8.43 & 0.27 & 0.82 \\
\hline SKK & 3.54 & 8.68 & 0.41 & 1.17 & 2.82 & 9.36 & 0.30 & 0.87 \\
\hline BRL & 10.94 & 16.44 & 0.67 & 1.87 & 9.93 & 17.17 & 0.58 & 1.63 \\
\hline CLP & 5.62 & 8.22 & 0.68 & 1.85 & 4.06 & 7.73 & 0.53 & 1.42 \\
\hline $\mathrm{COP}$ & 9.90 & 8.17 & 1.21 & 3.28 & 6.98 & 8.74 & 0.80 & 2.16 \\
\hline PLN & 3.52 & 9.41 & 0.37 & 0.97 & -2.08 & 10.77 & -0.19 & -0.50 \\
\hline TRY & 9.22 & 13.41 & 0.69 & 1.67 & 7.16 & 15.24 & 0.47 & 1.14 \\
\hline HUF & 1.28 & 9.31 & 0.14 & 0.33 & 2.27 & 10.29 & 0.22 & 0.52 \\
\hline ARS & 3.21 & 7.81 & 0.41 & 0.92 & 0.60 & 8.98 & 0.07 & 0.15 \\
\hline RON & 9.70 & 7.71 & 1.26 & 1.89 & 7.06 & 8.10 & 0.87 & 1.31 \\
\hline MYR & 1.59 & 3.35 & 0.47 & 0.58 & 2.43 & 3.50 & 0.69 & 0.85 \\
\hline \multicolumn{9}{|l|}{ Developed } \\
\hline$\overline{\mathrm{AUD}}$ & 0.72 & 9.47 & 0.08 & 0.25 & -0.52 & 9.86 & -0.05 & -0.17 \\
\hline CAD & 0.76 & 5.92 & 0.13 & 0.42 & 0.71 & 5.93 & 0.12 & 0.39 \\
\hline GBP & -1.50 & 6.24 & -0.24 & -0.78 & -1.99 & 6.51 & -0.31 & -0.99 \\
\hline JPY & 1.57 & 8.84 & 0.18 & 0.58 & 2.01 & 9.85 & 0.20 & 0.66 \\
\hline EUR & 3.84 & 7.96 & 0.48 & 1.57 & 3.51 & 8.29 & 0.42 & 1.38 \\
\hline CHF & 0.77 & 8.01 & 0.10 & 0.31 & -0.65 & 8.37 & -0.08 & -0.25 \\
\hline NOK & 0.69 & 8.13 & 0.09 & 0.28 & 0.43 & 8.41 & 0.05 & 0.17 \\
\hline SEK & 2.28 & 8.76 & 0.26 & 0.85 & 0.93 & 9.22 & 0.10 & 0.33 \\
\hline NZD & 2.12 & 10.71 & 0.20 & 0.64 & 2.65 & 11.01 & 0.24 & 0.78 \\
\hline \multicolumn{9}{|c|}{ Portfolios - equally weighted } \\
\hline$\overline{\mathrm{EM}}$ & 4.51 & 3.97 & 1.14 & 3.70 & 2.77 & 4.06 & 0.68 & 2.22 \\
\hline DEV & 1.25 & 5.01 & 0.25 & 0.81 & 0.79 & 5.12 & 0.15 & 0.50 \\
\hline ALL & 2.88 & 3.79 & 0.76 & 2.47 & 1.78 & 3.86 & 0.46 & 1.50 \\
\hline \multicolumn{9}{|c|}{ Portfolios - volatility weighted } \\
\hline$\overline{\mathrm{EM}}$ & 4.00 & 2.81 & 1.43 & 4.64 & 2.84 & 2.91 & 0.98 & 3.18 \\
\hline $\mathrm{DEV}$ & 1.20 & 4.81 & 0.25 & 0.81 & 0.77 & 4.93 & 0.16 & 0.51 \\
\hline ALL & 2.60 & 3.29 & 0.79 & 2.57 & 1.81 & 3.31 & 0.55 & 1.78 \\
\hline
\end{tabular}

Note: The table shows the average return (in annualized percentage points), standard deviation, the Sharpe ratio and its $t$-value for the technical trading strategies strategies moving averages rules $(M A)$ and support and resistance rules $(S E R R)$ applied to all exchange rates over their floating currency regime periods (see Table 1). The six bottom lines report the same statistics for equally-weighted and volatility-weighted portfolios for emerging markets (EM), for developed markets (DEV), and for all markets (ALL). 
Table 5: Performance of combined chartist trading strategy

\begin{tabular}{|c|c|c|c|c|c|c|c|}
\hline & Mean & Stdev & Sharpe & $t$-value & \#TR & BETC & CORR \\
\hline \multicolumn{8}{|c|}{ Emerging } \\
\hline$\overline{\mathrm{TWD}}$ & 4.62 & 4.08 & 1.13 & 3.68 & 4.32 & 0.53 & 0.81 \\
\hline PEN & 1.54 & 2.71 & 0.57 & 1.57 & 4.77 & 0.16 & 0.87 \\
\hline INR & 2.36 & 4.22 & 0.56 & 1.82 & 3.98 & 0.30 & 0.95 \\
\hline MXN & -4.29 & 9.11 & -0.47 & -1.53 & 6.26 & -0.34 & 0.77 \\
\hline ZAR & 3.48 & 13.73 & 0.25 & 0.83 & 5.34 & 0.33 & 0.90 \\
\hline CZK & 1.89 & 10.33 & 0.18 & 0.57 & 5.83 & 0.16 & 0.89 \\
\hline ILS & 3.27 & 5.90 & 0.55 & 1.71 & 5.20 & 0.31 & 0.88 \\
\hline THB & 4.63 & 8.32 & 0.56 & 1.72 & 4.73 & 0.49 & 0.86 \\
\hline PHP & 1.90 & 6.38 & 0.30 & 0.92 & 4.39 & 0.22 & 0.89 \\
\hline IDR & 11.73 & 19.77 & 0.59 & 1.82 & 5.13 & 1.14 & 0.76 \\
\hline KRW & 3.55 & 8.02 & 0.44 & 1.34 & 5.55 & 0.32 & 0.91 \\
\hline SKK & 3.18 & 8.82 & 0.36 & 1.04 & 5.42 & 0.29 & 0.91 \\
\hline BRL & 10.43 & 16.60 & 0.63 & 1.77 & 4.82 & 1.08 & 0.95 \\
\hline CLP & 4.84 & 7.74 & 0.63 & 1.69 & 4.96 & 0.49 & 0.88 \\
\hline $\mathrm{COP}$ & 8.44 & 8.34 & 1.01 & 2.74 & 4.41 & 0.96 & 0.95 \\
\hline PLN & 0.72 & 9.79 & 0.07 & 0.19 & 5.86 & 0.06 & 0.88 \\
\hline TRY & 8.19 & 13.71 & 0.60 & 1.45 & 5.33 & 0.77 & 0.83 \\
\hline HUF & 1.77 & 9.35 & 0.19 & 0.45 & 6.02 & 0.15 & 0.82 \\
\hline ARS & 1.90 & 8.20 & 0.23 & 0.52 & 5.36 & 0.18 & 0.91 \\
\hline $\mathrm{RON}$ & 8.38 & 7.76 & 1.08 & 1.62 & 4.71 & 0.89 & 0.93 \\
\hline MYR & 2.01 & 3.29 & 0.61 & 0.75 & 4.56 & 0.22 & 0.84 \\
\hline \multicolumn{8}{|c|}{ Developed } \\
\hline$\overline{\mathrm{AUD}}$ & 0.10 & 9.32 & 0.01 & 0.04 & 5.97 & 0.01 & 0.86 \\
\hline CAD & 0.73 & 5.73 & 0.13 & 0.42 & 5.84 & 0.06 & 0.87 \\
\hline GBP & -1.74 & 6.08 & -0.29 & -0.93 & 6.21 & -0.14 & 0.82 \\
\hline JPY & 1.79 & 9.09 & 0.20 & 0.64 & 5.72 & 0.16 & 0.89 \\
\hline EUR & 3.68 & 7.88 & 0.47 & 1.52 & 5.57 & 0.33 & 0.88 \\
\hline $\mathrm{CHF}$ & 0.06 & 7.82 & 0.01 & 0.02 & 6.01 & 0.00 & 0.82 \\
\hline NOK & 0.56 & 7.98 & 0.07 & 0.23 & 6.08 & 0.05 & 0.86 \\
\hline SEK & 1.61 & 8.70 & 0.18 & 0.60 & 5.68 & 0.14 & 0.87 \\
\hline NZD & 2.38 & 10.52 & 0.23 & 0.74 & 5.87 & 0.20 & 0.88 \\
\hline \multicolumn{8}{|c|}{ Portfolios - equally weighted } \\
\hline$\overline{\mathrm{EM}}$ & 3.64 & 3.78 & 0.96 & 3.14 & 5.11 & 0.36 & 0.77 \\
\hline DEV & 1.02 & 4.94 & 0.21 & 0.67 & 5.88 & 0.09 & 0.90 \\
\hline ALL & 2.33 & 3.71 & 0.63 & 2.05 & 5.49 & 0.21 & 0.88 \\
\hline \multicolumn{8}{|c|}{ Portfolios - volatility weighted } \\
\hline$\overline{\mathrm{EM}}$ & 3.42 & 2.64 & 1.30 & 4.22 & 4.76 & 0.36 & 0.71 \\
\hline DEV & 0.98 & 4.75 & 0.21 & 0.67 & 5.88 & 0.08 & 0.90 \\
\hline ALL & 2.20 & 3.19 & 0.69 & 2.25 & 5.32 & 0.21 & 0.87 \\
\hline
\end{tabular}

Note: The table shows performance statistics for the equally-weighted chartist strategy combining signals from the moving average rules $(M A)$ and support and resistance rules $(S E S R)$, applied to all exchange rates over their floating currency regime periods (see Table 1). See Table 3 for further details. 
Table 6: Performance of equally-weighted fundamentalist-chartist trading strategy

\begin{tabular}{lrrrrrrr}
\hline \hline & Mean & Stdev & Sharpe & t-value & \#TR & BETC & CORR \\
\hline Emerging & & & & & & & \\
TWD & 2.19 & 2.86 & 0.76 & 2.48 & 2.88 & 0.38 & -0.20 \\
PEN & 1.89 & 1.98 & 0.96 & 2.62 & 2.91 & 0.33 & 0.10 \\
INR & 2.67 & 2.15 & 1.24 & 4.03 & 2.49 & 0.54 & -0.43 \\
MXN & 0.47 & 5.51 & 0.09 & 0.28 & 3.34 & 0.07 & -0.14 \\
ZAR & 4.00 & 10.41 & 0.38 & 1.25 & 2.81 & 0.71 & -0.01 \\
CZK & 3.37 & 7.04 & 0.48 & 1.49 & 3.46 & 0.49 & 0.19 \\
ILS & 1.93 & 3.49 & 0.55 & 1.71 & 3.04 & 0.32 & -0.30 \\
THB & 4.16 & 4.82 & 0.86 & 2.66 & 2.92 & 0.71 & 0.03 \\
PHP & 3.30 & 4.60 & 0.72 & 2.21 & 2.33 & 0.71 & -0.24 \\
IDR & 11.44 & 17.40 & 0.66 & 2.01 & 2.81 & 2.04 & 0.29 \\
KRW & 3.17 & 6.86 & 0.46 & 1.39 & 3.32 & 0.48 & 0.23 \\
SKK & 3.92 & 5.93 & 0.66 & 1.90 & 2.98 & 0.66 & 0.05 \\
BRL & 10.89 & 11.34 & 0.96 & 2.70 & 2.63 & 2.07 & 0.03 \\
CLP & 3.04 & 5.83 & 0.52 & 1.41 & 2.99 & 0.51 & 0.09 \\
COP & 7.90 & 5.12 & 1.54 & 4.18 & 2.89 & 1.37 & -0.07 \\
PLN & 5.34 & 8.15 & 0.65 & 1.70 & 3.34 & 0.80 & 0.56 \\
TRY & 15.60 & 11.42 & 1.37 & 3.32 & 2.84 & 2.75 & 0.21 \\
HUF & 7.14 & 8.96 & 0.80 & 1.90 & 3.23 & 1.11 & 0.53 \\
ARS & 2.04 & 4.98 & 0.41 & 0.92 & 3.08 & 0.33 & 0.28 \\
RON & 4.78 & 3.89 & 1.23 & 1.81 & 2.59 & 0.92 & -0.20 \\
MYR & 1.01 & 1.65 & 0.61 & 0.75 & 2.28 & 0.22 & 0.00 \\
Developed & & & & & & & \\
AUD & 2.65 & 6.11 & 0.43 & 1.41 & 3.63 & 0.37 & 0.04 \\
CAD & 0.32 & 3.31 & 0.10 & 0.32 & 3.58 & 0.05 & -0.02 \\
GBP & -0.09 & 4.64 & -0.02 & -0.06 & 3.56 & -0.01 & 0.24 \\
JPY & 3.62 & 6.33 & 0.57 & 1.85 & 3.00 & 0.60 & -0.08 \\
EUR & 5.05 & 6.13 & 0.82 & 2.67 & 3.02 & 0.84 & 0.37 \\
CHF & 1.82 & 5.58 & 0.33 & 1.06 & 3.19 & 0.29 & 0.02 \\
NOK & 0.22 & 4.93 & 0.04 & 0.14 & 3.59 & 0.03 & 0.00 \\
SEK & 1.25 & 5.54 & 0.23 & 0.73 & 3.51 & 0.18 & 0.14 \\
NZD & 3.52 & 7.50 & 0.47 & 1.52 & 3.18 & 0.55 & 0.25 \\
Portfolios - equally weighted & & & & & \\
EM & 4.26 & 3.13 & 1.36 & 4.40 & 2.93 & 0.73 & 0.20 \\
DEV & 2.04 & 3.18 & 0.64 & 2.08 & 3.36 & 0.30 & 0.23 \\
ALL & 3.15 & 2.48 & 1.27 & 4.11 & 3.15 & 0.50 & 0.15 \\
Portfolios - volatility & weighted & & & & & \\
EM & 3.18 & 2.12 & 1.50 & 4.86 & 2.63 & 0.61 & -0.07 \\
DEV & 1.96 & 2.98 & 0.66 & 2.13 & 3.24 & 0.30 & 0.22 \\
ALL & 2.57 & 2.01 & 1.28 & 4.14 & 2.94 & 0.44 & 0.05 \\
\hline
\end{tabular}

Note: The table shows performance statistics for the equally-weighted fundamentalistchartist strategy applied to all exchange rates over their floating currency regime periods (see Table 1). See Table 3 for further details. 
Table 7: Performance of dynamic combined fundamentalist-chartist trading strategy

\begin{tabular}{|c|c|c|c|c|c|c|c|c|}
\hline & \multicolumn{4}{|c|}{ Dynamic weights } & \multicolumn{4}{|c|}{ Equally-weighted } \\
\hline & Mean & Stdev & Sharpe & $t$-value & Mean & Stdev & Sharpe & $t$-value \\
\hline \multicolumn{9}{|l|}{ Emerging } \\
\hline TWD & 2.62 & 2.81 & 0.93 & 2.71 & 2.33 & 1.83 & 1.28 & 3.72 \\
\hline PEN & 2.63 & 2.17 & 1.21 & 2.95 & 2.52 & 2.01 & 1.25 & 3.05 \\
\hline INR & 3.33 & 2.61 & 1.28 & 3.72 & 2.86 & 2.23 & 1.29 & 3.75 \\
\hline MXN & 3.17 & 7.97 & 0.40 & 1.16 & 0.67 & 5.83 & 0.12 & 0.34 \\
\hline ZAR & 8.14 & 15.18 & 0.54 & 1.56 & 4.03 & 11.23 & 0.36 & 1.04 \\
\hline CZK & 0.47 & 6.97 & 0.07 & 0.17 & 2.81 & 6.79 & 0.41 & 1.02 \\
\hline ILS & 2.39 & 4.36 & 0.55 & 1.35 & 2.15 & 3.68 & 0.58 & 1.43 \\
\hline THB & 5.06 & 3.82 & 1.32 & 3.22 & 5.28 & 3.25 & 1.63 & 3.96 \\
\hline PHP & 4.12 & 2.99 & 1.38 & 3.35 & 3.16 & 2.08 & 1.52 & 3.70 \\
\hline IDR & 5.84 & 8.03 & 0.73 & 1.76 & 5.41 & 7.14 & 0.76 & 1.83 \\
\hline KRW & 4.34 & 5.94 & 0.73 & 1.72 & 4.42 & 5.04 & 0.88 & 2.06 \\
\hline SKK & 2.61 & 7.27 & 0.36 & 0.78 & 3.77 & 6.16 & 0.61 & 1.32 \\
\hline BRL & 22.77 & 13.15 & 1.73 & 3.60 & 15.81 & 11.94 & 1.32 & 2.76 \\
\hline CLP & 4.20 & 6.88 & 0.61 & 1.18 & 3.04 & 6.50 & 0.47 & 0.91 \\
\hline $\mathrm{COP}$ & 13.29 & 6.43 & 2.07 & 4.00 & 10.33 & 5.79 & 1.78 & 3.46 \\
\hline PLN & 3.64 & 8.73 & 0.42 & 0.74 & 4.37 & 8.62 & 0.51 & 0.90 \\
\hline TRY & 3.66 & 12.58 & 0.29 & 0.44 & 5.76 & 7.28 & 0.79 & 1.21 \\
\hline HUF & -2.98 & 7.58 & -0.39 & -0.57 & 0.49 & 6.62 & 0.07 & 0.11 \\
\hline ARS & -1.05 & 0.81 & -1.29 & -1.53 & -0.67 & 0.71 & -0.94 & -1.12 \\
\hline RON & 5.66 & 5.39 & 1.05 & 0.80 & 6.39 & 3.81 & 1.68 & 1.28 \\
\hline MYR & NA & NA & NA & NA & NA & NA & NA & NA \\
\hline \multicolumn{9}{|l|}{ Developed } \\
\hline$\overline{\mathrm{AUD}}$ & 4.04 & 8.07 & 0.50 & 1.46 & 2.38 & 6.50 & 0.37 & 1.07 \\
\hline CAD & -0.72 & 3.73 & -0.19 & -0.56 & -0.05 & 3.01 & -0.02 & -0.05 \\
\hline GBP & 1.17 & 5.21 & 0.22 & 0.65 & 1.00 & 4.74 & 0.21 & 0.61 \\
\hline JPY & 3.05 & 5.92 & 0.52 & 1.50 & 2.45 & 5.20 & 0.47 & 1.38 \\
\hline EUR & 4.89 & 5.93 & 0.83 & 2.41 & 5.12 & 5.76 & 0.89 & 2.59 \\
\hline $\mathrm{CHF}$ & 2.24 & 6.86 & 0.33 & 0.95 & 1.55 & 4.97 & 0.31 & 0.91 \\
\hline NOK & -0.42 & 6.15 & -0.07 & -0.20 & -0.01 & 5.04 & 0.00 & 0.00 \\
\hline SEK & 0.47 & 6.84 & 0.07 & 0.20 & 1.65 & 5.75 & 0.29 & 0.84 \\
\hline NZD & 5.52 & 8.39 & 0.66 & 1.92 & 4.36 & 7.89 & 0.55 & 1.61 \\
\hline \multicolumn{9}{|c|}{ Portfolios - equally weighted } \\
\hline$\overline{\mathrm{EM}}$ & 4.41 & 3.46 & 1.27 & 3.72 & 3.32 & 2.97 & 1.12 & 3.26 \\
\hline DEV & 2.25 & 3.46 & 0.65 & 1.90 & 2.05 & 3.23 & 0.64 & 1.85 \\
\hline ALL & 3.33 & 2.86 & 1.16 & 3.39 & 2.69 & 2.61 & 1.03 & 3.00 \\
\hline \multicolumn{9}{|c|}{ Portfolios - volatility weighted } \\
\hline$\overline{\mathrm{EM}}$ & 1.92 & 1.30 & 1.48 & 4.31 & 1.63 & 1.16 & 1.41 & 4.10 \\
\hline DEV & 2.03 & 3.34 & 0.61 & 1.77 & 1.89 & 3.11 & 0.61 & 1.77 \\
\hline ALL & 1.97 & 2.00 & 0.99 & 2.88 & 1.76 & 1.86 & 0.95 & 2.76 \\
\hline
\end{tabular}

Note: The table shows performance statistics for the combined fundamentalist-chartist strategy with weights determined by the relative performance during the past 12 months, applied to all exchange rates over their floating currency regime periods in the period 1999-2007 (see Table 1). See Table 3 for further details. 


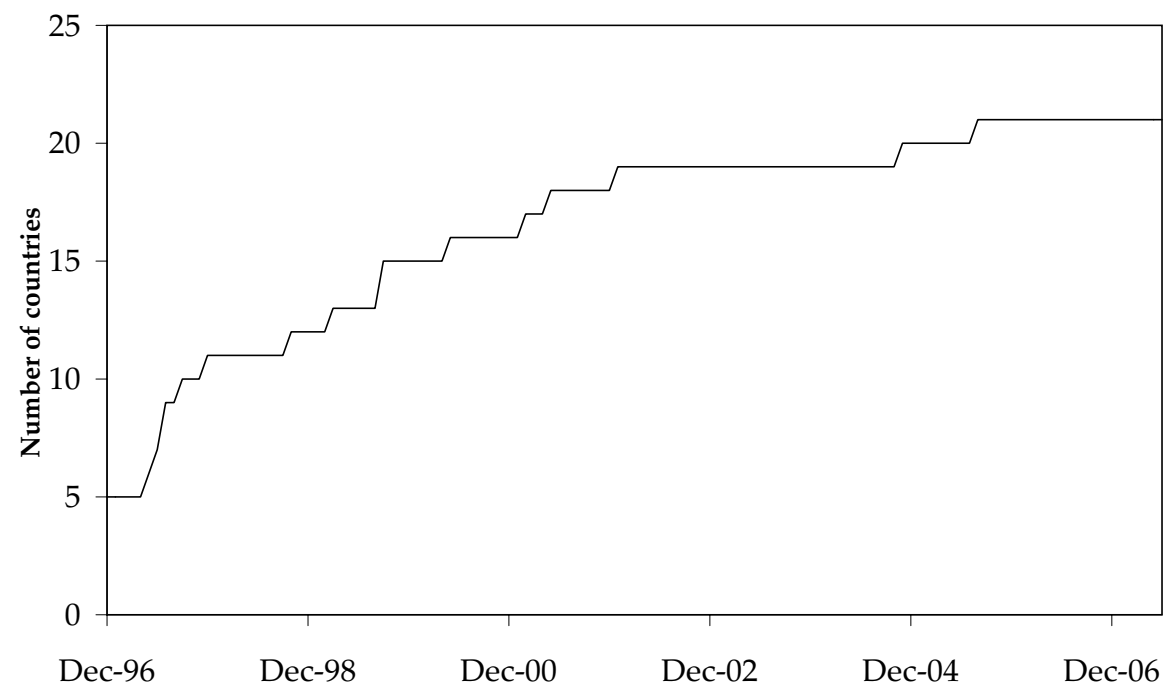

Figure 1: Number of emerging market countries with floating exchange rate regime, December 1996 - June 2007. 


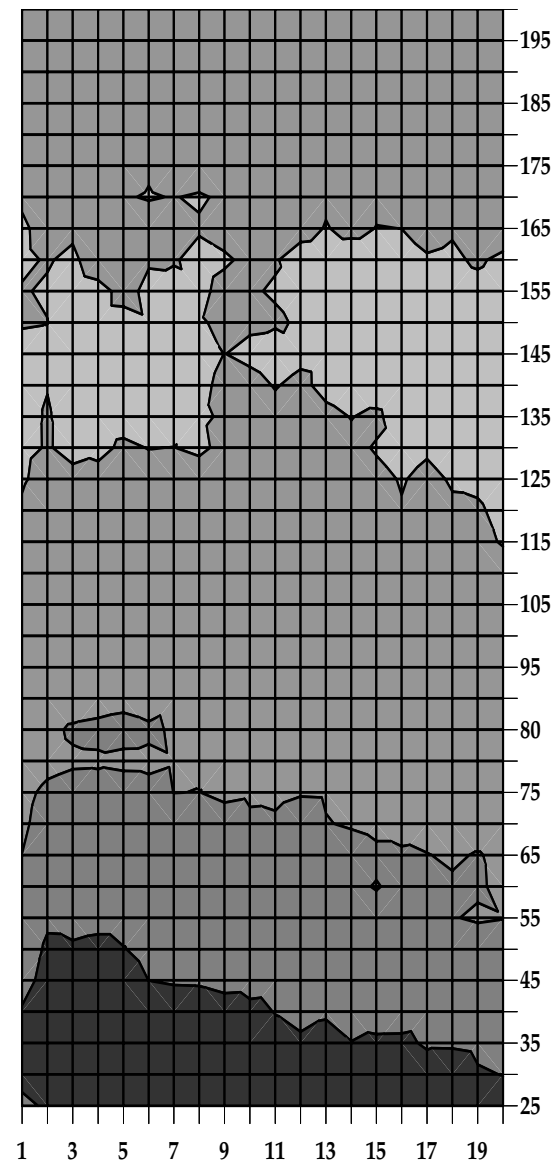

Short term MA (days)

(a) Emerging Markets

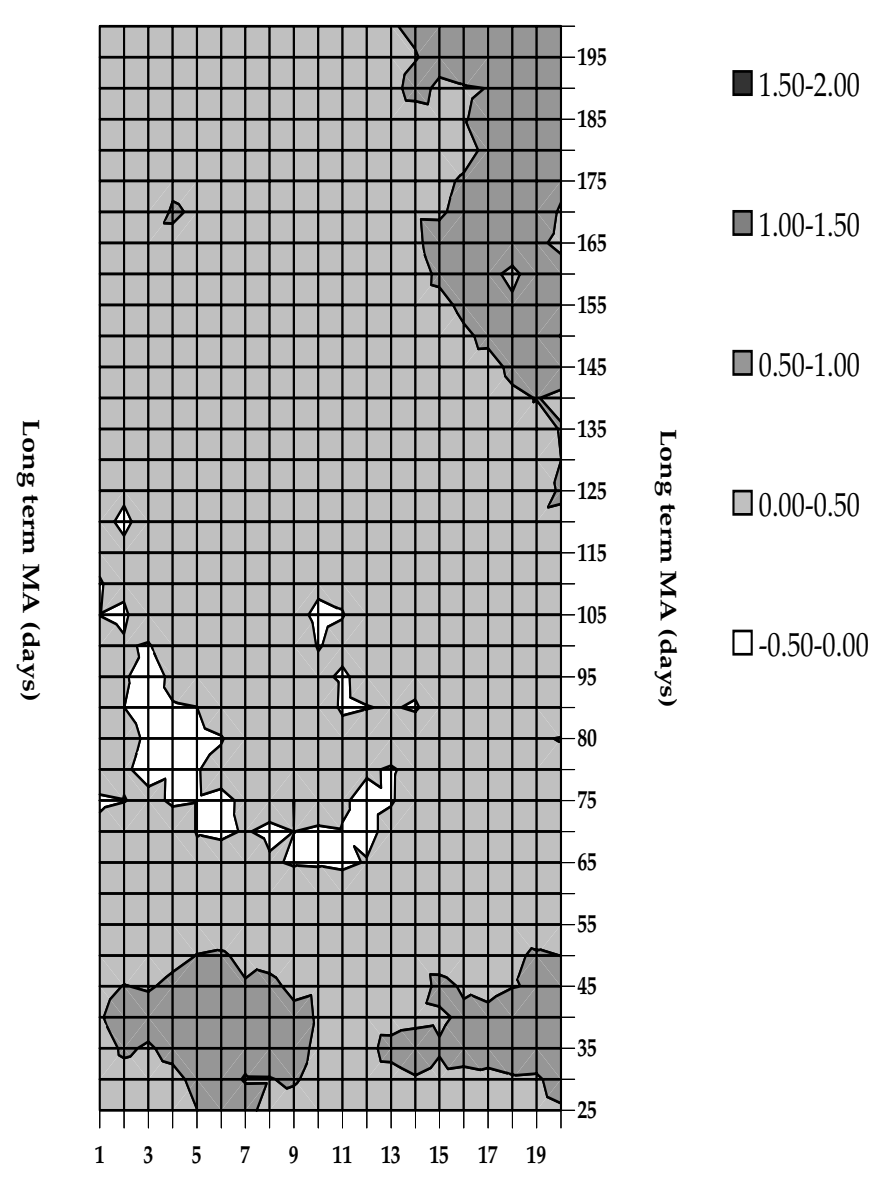

Short term MA (days)

(b) Developed Markets

Figure 2: Heat-map of the average $t$-values for moving average strategies with the short term moving average ranging between 1 - 20 days and the long term moving average between $25-200$ days. The average $t$-value of the emerging markets in panel a) is based the average of 21 emerging market currencies. The developed market average in panel b) is based on nine developed market currencies. See Section 2 for details. 


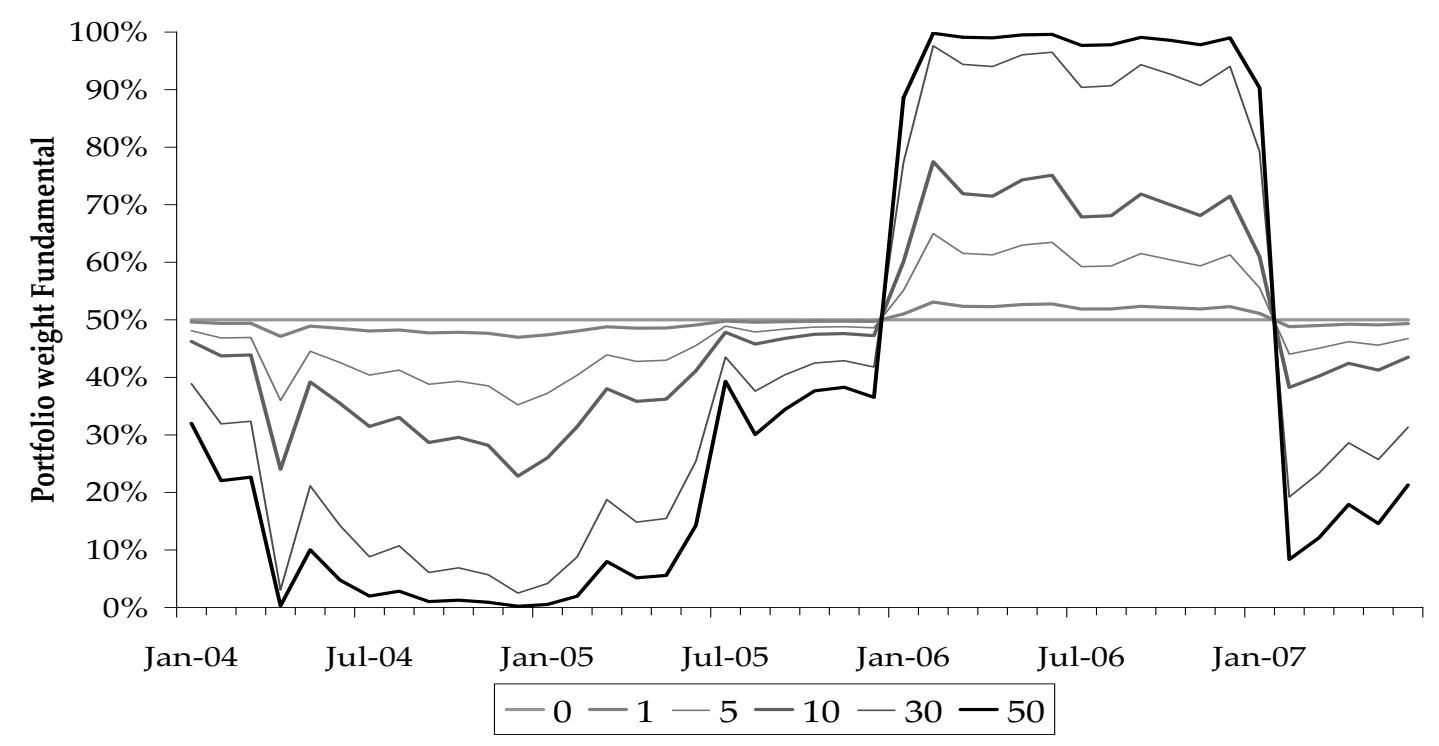

Figure 3: Sensitivity of the dynamic weights in the combined fundamental-technical trading strategy to the choice of $\gamma$ in $(11)$ (with $J=12$ ) for the Korean won. 


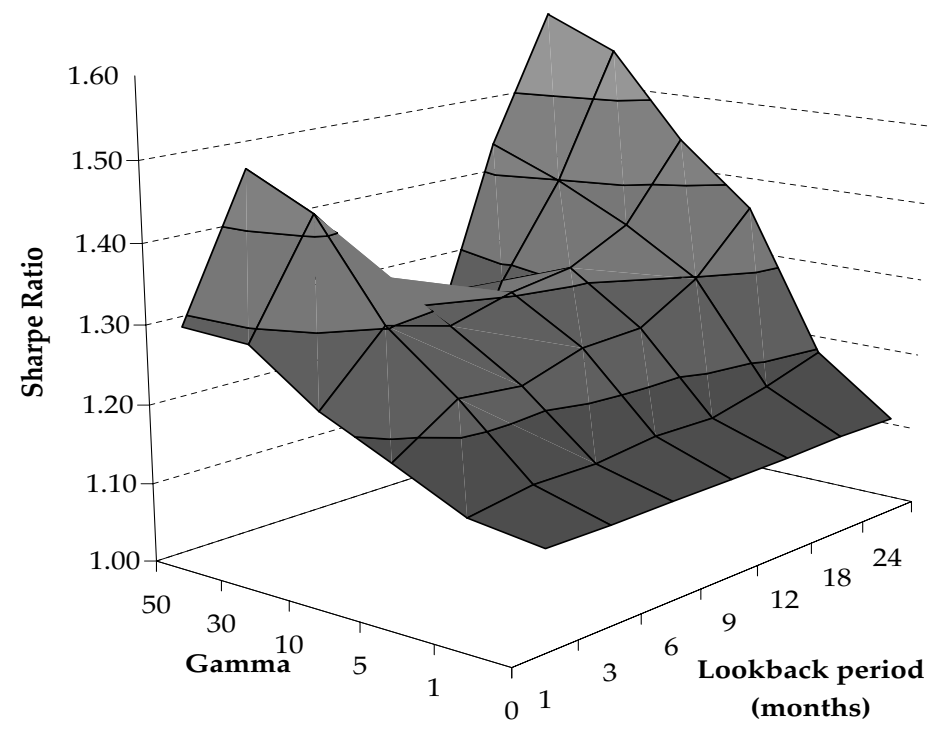

(a) Emerging Markets

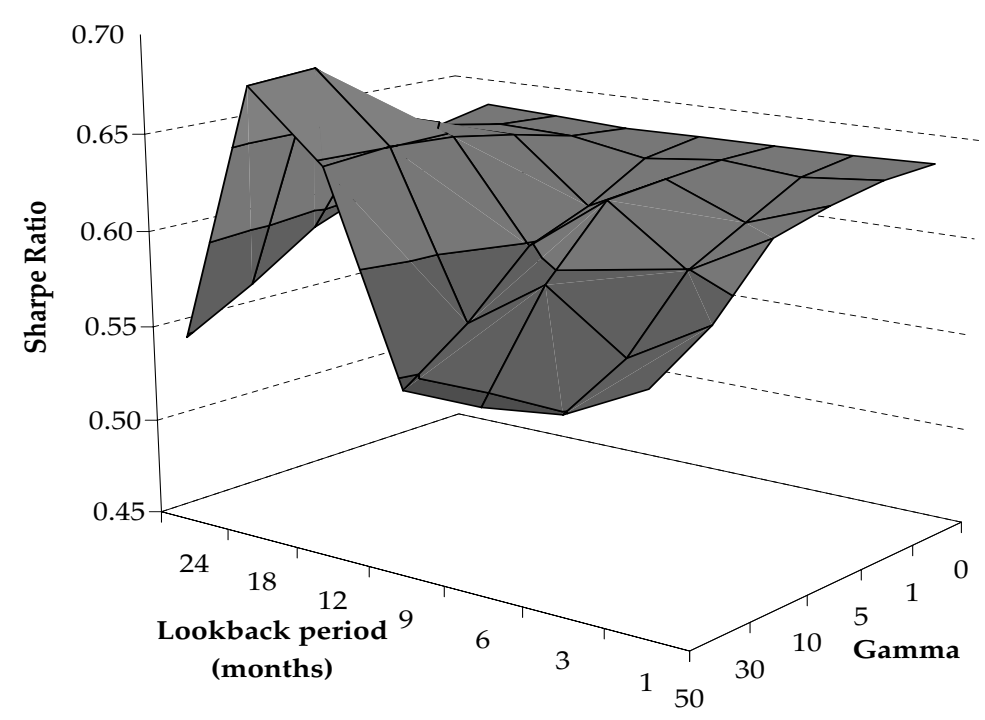

(b) Developed Markets

Figure 4: Dynamic weighting between fundamentalist and chartist rules. The figure shows the Sharpe ratio of the dynamically weighted portfolio for different lookback periods $J$ ranging from 1 to 24 months and for different 'aggressiveness' of the dynamic strategy as measured by $\gamma$. Here $\gamma=0$ corresponds to the naive equallyweighted strategy, while $\gamma=50$ corresponds to the most aggressive strategy, with weights changes the fastest. 


\section{Publications in the Report Series Research ${ }^{*}$ in Management}

\section{ERIM Research Program: "Finance and Accounting"}

2007

Revisiting Uncovered Interest Rate Parity: Switching Between UIP and the Random Walk

Ronald Huisman and Ronald Mahieu

ERS-2007-001-F\&A

http://hdl.handle.net/1765/8288

Hourly Electricity Prices in Day-Ahead Markets

Ronald Huisman, Christian Huurman and Ronald Mahieu

ERS-2007-002-F\&A

http://hdl.handle.net/1765/8289

Do Exchange Rates Move in Line with Uncovered Interest Parity?

Ronald Huisman, Ronald Mahieu and Arjen Mulder

ERS-2007-012-F\&A

http://hdl.handle.net/1765/8993

Hedging Exposure to Electricity Price Risk in a Value at Risk Framework

Ronald Huisman, Ronald Mahieu and Felix Schlichter

ERS-2007-013-F\&A

http://hdl.handle.net/1765/8995

Corporate Governance and Acquisitions: Acquirer Wealth Effects in the Netherlands

Abe de Jong, Marieke van der Poel and Michiel Wolfswinkel

ERS-2007-016-F\&A

$\underline{\text { http://hdl.handle.net/1765/9403 }}$

The Effect of Monetary Policy on Exchange Rates during Currency Crises; The Role of Debt, Institutions and Financial Openness

Sylvester C.W. Eijffinger and Benedikt Goderis

ERS-2007-022-F\&A

http://hdl.handle.net/1765/9725

Do Private Equity Investors Take Firms Private for Different Reasons?

Jana P. Fidrmuc, Peter Roosenboom and Dick van Dijk

ERS-2007-028-F\&A

http://hdl.handle.net/1765/10070

The Influence of Temperature on Spike Probability in Day-Ahead Power Prices

Ronald Huisman

ERS-2007-039-F\&A

http://hdl.handle.net/1765/10179

Costs and Recovery Rates in the Dutch Liquidation-Based Bankruptcy System

Oscar Couwenberg and Abe de Jong

ERS-2007-041-F\&A

http://hdl.handle.net/1765/10461

The Volatility Effect: Lower Risk without Lower Return

David C. Blitz and Pim van Vliet

ERS-2007-044-F\&A

http://hdl.handle.net/1765/10460 
Strategic Debt: Evidence from Bertrand and Cournot Competition

Abe de Jong, Thuy Thu Nguyen and Mathijs A. van Dijk

ERS-2007-057-F\&A

http://hdl.handle.net/1765/10504

Capital Structure Around the World: The Roles of Firm- and Country-Specific Determinants

Abe de Jong, Rezaul Kabir and Thuy Thu Nguyen

ERS-2007-058-F\&A

http://hdl.handle.net/1765/10517

The Effects of Federal Funds Target Rate Changes on S\&P100 Stock Returns, Volatilities, and Correlations Helena Chulia-Soler, Martin Martens and Dick van Dijk ERS-2007-066-F\&A

http://hdl.handle.net/1765/10610

Industry Valuation Driven Earnings Management

Tao Jiao, Gerard Mertens and Peter Roosenboom

ERS-2007-069-F\&A

http://hdl.handle.net/1765/10608

The Impact of Media Attention on the Use of Alternative Earnings Measures

Miriam Koning, Gerard Mertens and Peter Roosenboom

ERS-2007-073-F\&A

http://hdl.handle.net/1765/10609

Irving Fisher and the UIP Puzzle: Meeting the Expectations a Century Later

Rachel A. Campbell, Kees G. Koedijk, James R. Lothian and Ronald J. Mahieu

ERS-2007-088-F\&A

http://hdl.handle.net/1765/10774

Electricity Portfolio Management: Optimal Peak / Off-Peak Allocations

Ronald Huisman, Ronald J. Mahieu and Felix Schlichter

ERS-2007-089-F\&A

http://hdl.handle.net/1765/10775

The Economic Value of Fundamental and Technical Information in Emerging Currency Markets

Gerben de Zwart, Thijs Markwat, Laurens Swinkels and Dick van Dijk

ERS-2007-096-F\&A

http://hdl.handle.net/1765/10891

A Recommitment Strategy for Long Term Private Equity Fund Investors

Gerben de Zwart, Brian Frieser and Dick van Dijk

ERS-2007-097-F\&A

http://hdl.handle.net/1765/10892

* A complete overview of the ERIM Report Series Research in Management: https://ep.eur.nl/handle/1765/1

ERIM Research Programs:

LIS Business Processes, Logistics and Information Systems

ORG Organizing for Performance

MKT Marketing

F\&A Finance and Accounting

STR Strategy and Entrepreneurship 